\title{
Optimal Monetary Policy under Sudden Stops*
}

\author{
Vasco Cúrdia \\ Federal Reserve Bank of New York $!$
}

February 14, 2008

\begin{abstract}
Emerging market economies often face sudden stops in capital inflows or reduced access to the international capital market. This paper analyzes what should monetary policy do in such an event. Optimal monetary policy induces a hike in interest rate and exchange rate depreciation. The latter mitigates the impact of the sudden stop in the domestic economy by boosting export revenues. In spite of that, a recession is not avoided. It is shown in the paper that the arrival of the sudden stop further increases the problem of time inconsistency of policy. Optimal policy is fairly well approximated by a flexible targeting rule, in which a combination of domestic prices, exchange rate and output is stabilized. We show that whether a fixed exchange rate regime is a good policy strategy, from a welfare perspective, depends on the economic environment. For the benchmark parameterization, the peg is the worst of simple rules considered. For alternative parameterizations, featuring low nominal rigidities or high elasticity of foreign demand, the fixed exchange rate regime performs relatively better.
\end{abstract}

Keywords: sudden stops, monetary policy, emerging markets, financial crises

JEL: E5, F3, F4

${ }^{*}$ The author thanks Michael Woodford for guidance and fruitful discussions. He also gratefully acknowledges suggestions and comments from Roc Armenter, Andrea Ferrero, Chris Sims and Lars Svensson. The views expressed in this paper are those of the author and do not necessarily reflect the position of the Federal Reserve Bank of New York or the Federal Reserve System.

${ }^{\dagger}$ Federal Reserve Bank of New York, 33 Liberty Street, 3rd Floor, New York, NY 10045. E-mail: vasco.curdia@ny.frb.org. 


\section{Optimal Monetary Policy under Sudden Stops}

\section{Introduction}

Emerging market economies are typically characterized as unstable environments subject to a variety of shocks that either do not affect the more developed countries or that are magnified due to lack of credibility of these economies. Caballero (2001) documents some of these issues and reaches the important conclusion that many of the problems of these economies are related to the recurrent loss of access to the international capital markets. Some of the episodes can go as far as to lead to an outbreak of sudden and sharp reversals in the financial account, the sort of which are described as "sudden stops" of capital inflows in the literature, following Calvo (1998).

These shocks affect the production capacity of the economy by restricting the sources for financing investment and imported inputs and thus increasing costs. The subsequent adjustment requires a reversal of the current account usually accompanied by a contraction in economic activity as a corollary of the increased cost of borrowing. ${ }^{1}$ The reduction in capital inflows also puts significant pressure on the exchange rate leading to significant devaluations and increased interest rates in order to reduce the draining of capital. As mentioned in Fraga et al. (2003) the shocks augment the trade-offs behind the conduct of monetary policy leading to higher volatility of inflation, output and interest rates.

The literature discusses extensively what the best policy regime for emerging markets might be (e.g. Mishkin (2000) and Mishkin and Savastano (2002)). This paper contributes to this literature by conducting a normative analysis of monetary policy in response to a sudden stop shock. In particular it looks at what is the optimal policy but it also discusses how do several simple rules rank amongst themselves and in comparison to the optimal policy. Furthermore, it discusses what the optimal simple rules are under alternative parameterizations and what is their performance relative to the optimal policy (not constrained to be a

\footnotetext{
${ }^{1}$ Calvo and Reinhart (2000) documment very well the dimension of these shocks and their consequences to the economy.
} 


\section{Optimal Monetary Policy under Sudden Stops}

simple rule).

Optimal policy should be understood as a benchmark for policy analysis and should entail a reaction to economic conditions that is not dependent on the timing of commitment. Otherwise authorities would always make a new "commitment" every period, losing credibility and eventually getting to be in discretion scenario, rather than in a true commitment. Therefore this paper considers optimal monetary policy in a "timeless perspective" as proposed in Woodford (1999). This criterion has the advantage that we constrain the set of alternatives to time-consistent policies, which adds credibility to them. The analysis thus avoids the time inconsistency problem typical in forward-looking models. ${ }^{2}$

Following the framework proposed in Cúrdia (2007), the economy is subject to shocks in foreigners' perceptions about the performance of the economy. These shocks lead to increases in the required risk premium demanded from domestic borrowers. This is modeled using a modified version of the financial accelerator initially proposed by Bernanke et al. (1999) and applied to an open economy by Gertler et al. (2003). The sudden stop is therefore considered to be exogenous to the economy and is unexpected, similarly to most of the literature on the subject.

In the event of a misperception shock the contraction in the financial account must be matched with an increase in the current account. This can be achieved in two ways: an increase in export revenues and/or a reduction in import expenditures. Optimal policy uses both. A common feature, across most parameterizations of the model, is that optimal monetary policy implies a depreciation of the domestic currency together with increased interest rates. The timing of the two can vary depending on the parameter configuration. In all parameterizations optimal policy implies a real depreciation of the currency. In most of the scenarios considered this is implemented through a nominal depreciation. In the baseline scenario the interest rates are kept low initially, when the shock arrives, but increase

\footnotetext{
${ }^{2}$ The time inconsistency of optimal policy dates back to the work of Kydland and Prescott (1977).
} 


\section{Optimal Monetary Policy under Sudden Stops}

significantly one period later.

The optimal policy just described implies that the interest rate increase imposes some adjustment on the part of the domestic economy towards less borrowing and consumption (of both domestic and foreign goods) and the real depreciation leads to increased export revenues and fewer imports. Therefore the current account is adjusting through both imports and exports. This contrasts to the case of a fixed exchange rate system in which the real exchange rate is not allowed to adjust as quickly forcing more of the adjustment on the domestic economy and imposing a stronger recession, that in this setting is also welfare reducing.

Optimal policy does not close the output gap as suggested in Hevia (2006) precisely because of the two distortions affecting the economy: monopolistic competition and the imperfect capital market. In order to oppose the two interferences Hevia (2006) finds that a labor tax should be used to eliminate the distortions from monopolistic competition and a capital tax to reduce the distortions from the imperfect capital market. Here none of those are present, leading to a negative output gap on impact, followed by a positive and persistent output gap.

The optimal path of the interest rate compares to the results of Braggion et al. (2005). These authors consider an economy that in normal circumstances has no credit constraints but is subject to the sudden imposition of collateral constraints limiting the availability of credit. Optimal policy under their calibration implies an increase of the interest rate on impact and subsequent gradual reduction, converging in the long run to levels below those verified before the arrival of the shock. In this paper the interest rate also increases (if not on impact at least one period afterwards) and also has a gradual fall. However it will not settle on levels below the initial steady state. The reason for these different results is that Braggion et al. (2005) assumes a permanent shock while here the shocks is expected to eventually disappear. Interestingly the interest rate does converge to the steady state level 


\section{Optimal Monetary Policy under Sudden Stops}

from below, implying that after the initial increase the interest rate will stay for time at levels just below the steady state ones.

The advantage of the framework used here is its big flexibility and easiness of use to compare alternative policies. In particular we can analyze the extent to which the sudden stop affects the time inconsistency pressures on policy. In particular we can compare the "timeless perspective" with the policy implied by a new commitment when the sudden stop arrives, sometimes also called Ramsey optimal policy. The timeless perspective optimal is time-consistent, while the Ramsey optimal is not as it ignores the expectations of agents formed in previous periods. A Ramsey policy exploits the export revenues dimension even further and delays the recession by one period, as long as there are enough nominal rigidities in the export sector. It does so by using a much larger devaluation and keeping initial interest rates lower. However, if nominal rigidities in the export sector are not present then the cost of using the devaluation channel increases because it translates into stronger cost pressures in the domestic retail sector and thus the Ramsey policy follows a path more consistent to the optimal path under "timeless perspective."

A comparison of simple rules shows that, from a welfare perspective, a peg is not the most desirable regime in the benchmark parametrization. In this parametrization, the peg is actually the worst of the simple rules considered. However, when considering alternative parameterizations, namely those featuring low nominal rigidities or high elasticity of foreign demand, the fixed exchange rate regime performs much better. Given that these are not unreasonable parameterizations the peg should not be eliminated from the list of possible monetary policy strategies to consider when addressing a sudden stop event. This is an important outcome because it shows that whether a fixed exchange rate regime is a good policy depends on the economic environment (or in the model, on the parametrization).

The class of rules considered include two broad types. The first consists of interest rate rules resembling the Taylor rule proposed in Taylor (1993), augmented to include some reac- 


\section{Optimal Monetary Policy under Sudden Stops}

tion to the exchange rate. The second group consists of targeting rules aimed at stabilizing inflation but also output and the exchange rate. A general result is that, within the class of rules considered, none manages to strictly implement the optimal policy. However a targeting rule aimed at stabilizing at the same time domestic price inflation, the exchange rate and output is the optimal simple rule and can get very close to the optimal policy. The weights on stabilizing the three components of the basket vary depending on the parameter configuration. In the baseline calibration the weight on inflation far outweights the other two, with the exchange rate receiving very small weight.

In the baseline calibration (and also for low elasticities of foreign demand) the optimal policy can close up to $98 \%$ of the welfare gap between the worst rule and the optimal policy (where worst policy is in this scenario the exchange rate peg). Consistent with this, the best rule implies paths for the variables that very closely resemble those under the optimal policy, especially so for the real variables (nominal variables' paths are not exactly matched). These two results together imply that even though flexible inflation targeting is not strictly the optimal policy it gets fairly close to implement it.

Many authors suggest inflation targeting for emerging markets - some examples are Mishkin and Savastano (2002), Caballero and Krishnamurthy (2005) and Fraga et al. (2003). Several emerging markets have successfully implemented inflation targeting frameworks (e.g. Chile and Brazil). The results presented here can be used to suggest that such regimes might be good policy frameworks for emerging markets also when it comes to coping with sudden stops. Indeed it can be argued that the sudden stop affecting Brazil in 2001 was short lived. Whether it was so due to the inflation targeting regime or not is not entirely clear but it is a fact that Brazil has been in recent years more resilient to political shocks that could escalate into crises as its history suggests.

This is not the only paper that looks at how alternative policy regimes cope with shocks to the credit conditions of an emerging market. The literature is actually fairly rich in such 


\section{Optimal Monetary Policy under Sudden Stops}

exercises. A short list of the ones more closely related are Gertler et al. (2003), Céspedes et al. (2004), Cook (2004), Devereux et al. (2006) and Cúrdia (2007). Most of these focus on a stabilization perspective. Devereux et al. (2006) is the only one which ranks the alternatives according to welfare. Cook (2004) is the only one in which economic conditions might suggest that a peg is the best regime, while all others show that flexible exchange rates and some rule in which interest rates react to inflation and output perform better. However none of the exercises makes an explicit comparison to the optimal policy. Furthermore none of the above consider targeting rules (except to the extent that a peg is itself very particular targeting rule). Therefore this paper presents a more comprehensive analysis of optimal monetary policy in a consistent framework. It is especially noteworthy the ability of this framework in studying under which environments does the fixed exchange rate regime perform better or worse.

The remainder of the paper is organized as follows. Section 2 presents the model in detail. Section 3 discusses the optimal monetary policy and compares it to the flexible price equilibrium. This is followed by an analysis of how different simple rules perform, in section 4. Section 5 concludes.

\section{The model}

The model follows very closely Cúrdia (2007). The main distinction is that here there is pricing to market and local currency pricing. ${ }^{3}$ Some functional forms were also simplified for the sake of simplicity. The domestic economy is populated by a representative household, firms and the monetary authority. The households consume, provide labor for the production of the domestic good and are the shareholders of the firms of the economy. The domestic

\footnotetext{
${ }^{3}$ This change does not change the broad picture of the economic dynamics but is crucial for the ability to characterize optimal monetary policy. Without PTM-LCP the first order and second order conditions are not satisfied. Furthermore some parameters also were changed for the same reason.
} 


\section{Optimal Monetary Policy under Sudden Stops}

good is produced in a perfectly competitive wholesale market. Retail firms then purchase the domestic good from the wholesale firms, convert it into their own varieties, and operate in a monopolistic competition environment setting prices, which are sticky a la Calvo. Each retail firm will sell its variety of the domestic goods to both the domestic and foreign households. However they will set prices differently in the two markets. Furthermore they will set prices in the local currency where the goods is being sold. The foreigners fulfill four roles: they sell inputs and lend money to the wholesale firms, they sell a final good to the domestic households and they purchase the domestic good. The remainder of this section describes in detail the model. ${ }^{4}$

\subsection{Households}

The representative household derives utility from consumption and disutility from labor, according to

$$
\sum_{t=0}^{\infty} \beta^{t} U\left(C_{t}, L_{t}\right),
$$

where $C_{t}$ refers to consumption and $L_{t}$ to labor, and

$$
U\left(C_{t}, L_{t}\right)=\frac{C_{t}^{1-\sigma}}{1-\sigma}-\frac{L_{t}^{1+\psi}}{1+\psi}
$$

The budget is spent in consumption (with $P_{t}$ denoting the consumption price index, CPI) and investment in domestic assets, $D_{t}$, which pay a return rate of $R_{t}$. The domestic assets exist in zero net supply so that, in equilibrium, $D_{t}=0$ at all times. The sources of income are the wage collected, $W_{t}$, profits from wholesalers, $\pi_{w, t}$, profits from the retailers, $\pi_{r, t}{ }^{5}$ and

\footnotetext{
${ }^{4}$ For easier reading of the paper I insert in appendix A tables listing all the variables (Table 1) and parameters (Table 2) of the model.

${ }^{5}$ Profits are defined more formally as $\pi_{w, t} \equiv \int_{0}^{1} \pi_{w, t}(j) d j$ and $\pi_{r, t} \equiv \int_{0}^{1} \pi_{r, t}(j) d j$.
} 


\section{Optimal Monetary Policy under Sudden Stops}

returns on domestic asset holdings:

$$
P_{t} C_{t}+D_{t} \leq R_{t-1} D_{t-1}+W_{t} L_{t}+\pi_{w, t}+\pi_{r, t}
$$

There is a no-Ponzi games condition, so that the problem is well defined,

$$
\lim _{T \rightarrow \infty} \prod_{s=0}^{T-1} R_{t+s}^{-1} D_{t+T} \geq 0 .
$$

The households are restricted from accessing the international capital markets and, therefore, cannot borrow or lend to foreigners. The only way households achieve some consumption smoothing is through their holdings of firms. These can use their net worth to borrow in the international capital market and give higher or lower dividends to their shareholders, the households. In spite of no direct access to foreign credit, there is still some indirect access, through firms' leverage.

The representative household maximizes (2.1) subject to (2.2). The resulting Euler equation for consumption is

$$
\frac{1}{R_{t}}=\beta E_{t}\left[\frac{C_{t+1}^{-\sigma}}{C_{t}^{-\sigma}} \frac{1}{\Pi_{t+1}}\right],
$$

with $\Pi_{t} \equiv P_{t} / P_{t-1}$ denoting gross inflation. Labor supply is described as

$$
\frac{W_{t}}{P_{t}}=L_{t}^{\psi} C_{t}^{\sigma}
$$

with $W_{t}$ the nominal wage.

The households consumption bundle is composed by domestic and foreign goods denoted by $C_{H, t}$ and $C_{F, t}$, respectively. Preferences over the two goods are Cobb-Douglas:

$$
C_{t}=\left(\frac{C_{H, t}}{\gamma}\right)^{\gamma}\left(\frac{C_{F, t}}{1-\gamma}\right)^{1-\gamma}
$$




\section{Optimal Monetary Policy under Sudden Stops}

The domestic good is purchased at price $P_{H, t}$. The law of one price is assumed for the imported final good, here assumed to be the same as the foreign CPI, $P_{t}^{*}$, which for simplicity is set to one at all times. Foreign currency denominated values are converted to domestic currency at the rate $S_{t}$. Cost minimization implies the following consumption schedules

$$
\begin{aligned}
C_{H, t} & =\gamma \frac{P_{t} C_{t}}{P_{H, t}} \\
C_{F, t} & =(1-\gamma) \frac{P_{t} C_{t}}{S_{t}}
\end{aligned}
$$

and the CPI is given by

$$
P_{t}=P_{H, t}^{\gamma} S_{t}^{1-\gamma}
$$

\subsection{Wholesale firms}

Wholesale firms operate as price takers in a competitive market. They hire labor, $L_{t}$, and purchase an imported input, $Z_{t}$, that is required for production but takes one period to process and be used. ${ }^{6}$ The technology used by firm $j$ is given by:

$$
Y_{t}(j)=\left(\frac{L_{t}(j)}{\alpha}\right)^{\alpha}\left(\frac{\omega_{t}(j) Z_{t-1}(j)}{1-\alpha}\right)^{1-\alpha}
$$

where $\omega_{t}(j)$ is an idiosyncratic shock to the productivity of the imported input that is i.i.d. across firms and time, with $E\left[\omega_{t}(j)\right]=1$, and is assumed to have a log-normal distribution, $\log \left(\omega_{t+1}(j)\right) \sim N\left(-\frac{1}{2} \sigma_{\omega}^{2}, \sigma_{\omega}^{2}\right)$

Given the available imported inputs, the labor demand can be expressed as

$$
L_{t}(j)=\alpha \frac{P_{w, t} Y_{t}(j)}{W_{t}}
$$

\footnotetext{
${ }^{6}$ The convention is that time subscript $t$ denotes variables known at $t$. Hence, $Z_{t}$ is the amount of imported input that is bought in period $t$, but available for use in period $t+1$.
} 


\section{Optimal Monetary Policy under Sudden Stops}

where $P_{w, t}$ is the wholesale price of the domestic good.

Define $R_{Z, t+1}(j)$ as the gross returns from investing one domestic currency unit in the imported input:

$$
R_{Z, t+1}(j) \equiv(1-\alpha) \frac{P_{w, t+1} Y_{t+1}(j)}{S_{t} Z_{t}(j)}
$$

with the imported inputs purchased at the foreign price level of one. ${ }^{7}$ Given the current assumptions for the production function, it is possible to show that we can write

$$
R_{Z, t+1}(j)=\omega_{t+1}(j) R_{Z, t+1}
$$

where $R_{Z, t+1}$ is the aggregate component, common to all firms.

At the end of the period each firm has available net worth in domestic currency, $N_{t}(j)$. In order to finance the imports of inputs for the next period it borrows from foreigners the difference between the value of its net worth and the expenditures in the imports. The debt to foreigners, $B_{t}$, is denominated in foreign currency, typical of emerging market economies (denominated the "original sin"). The balance sheet of the firm is given by

$$
S_{t} B_{t}(j)=S_{t} Z_{t}(j)-N_{t}(j)
$$

Foreign lenders have misperceptions about the distribution of the imported input productivity $\omega_{t+1}(j)$. This Knightian uncertainty is represented as

$$
\omega_{t+1}^{*}(j)=\omega_{t+1}(j) \kappa_{t},
$$

where $\omega_{t+1}^{*}(j)$ refers to foreigners perceptions about $\omega_{t+1}(j)$ and $\kappa_{t}$ is the misperception factor. If $\kappa_{t}=1$ then there is no misperception (the normal case); and if $\kappa_{t} \neq 1$ then the

\footnotetext{
${ }^{7}$ Once more assuming the price of imported inputs to be the same as foreign CPI, and this to be one at all times is just for simplicity, without any loss of generality for the analysis in this paper.
} 


\section{Optimal Monetary Policy under Sudden Stops}

perceived distribution is different from the true one. During sudden stop periods, ambiguity about the distribution for the next period can be described by allowing $\kappa_{t}$ to have support over a given interval of values, $\left[\kappa_{s s}, \kappa^{s s}\right]$. Lenders deal with the Knightian uncertainty through a max-min criterion, as in Gilboa and Schmeidler (1989), or, in other words, that in the face of uncertainty about the underlying distribution they will pick the worst case scenario. This is what can be interpreted as "ambiguity aversion" as described in Backus et al. (2004). As a consequence, in a sudden stop period, they will take the worst case scenario, $\kappa_{s s}$, as the mean of the distribution of $\omega_{t+1}(j)$, instead of one.

The sudden stop is then defined as the state in which foreign lenders face the Knightian uncertainty, a state denoted by $\mathcal{S}_{t}=\mathcal{U}$. The normal state, is denoted by $\mathcal{S}_{t}=\mathcal{N}$. Before any shock takes place the economy is in state $\mathcal{S}_{t}=\mathcal{N}$. A change to $\mathcal{S}_{t}=\mathcal{U}$ is unexpected by the agents. If a sudden stop takes place, there is a probability of reverting to the normal state, given by $\operatorname{Pr}\left[\mathcal{S}_{t+1}=\mathcal{N} \mid \mathcal{S}_{t}=\mathcal{U}\right]=\delta_{n}$. Once the economy returns to its normal state, a shift back to $\mathcal{S}_{t}=\mathcal{U}$ cannot occur and therefore this is a one time sudden stop. ${ }^{8}$

The risk free opportunity cost for the foreigners is the international interest rate, $R^{*}$, assumed to be constant. However that is not the interest rate charged to the firms on their debt, because of the uncertain productivity of the firms, implying risk for the creditors. The foreign lenders are risk neutral (after the knightian uncertainty is sorted out). Following Bernanke and Gertler (1989), the problem is set as one of "costly state verification." This implies that, in order to verify the realized idiosyncratic return, the lender has to pay a cost, consisting of a fraction of those returns, so that the total cost of verification, in foreign currency, is $\mu \frac{\omega_{t+1}(j) R_{Z, t+1} S_{t} Z_{t}(j)}{S_{t+1}}$. The debt contract is, then, characterized by a default threshold and a contractual interest rate. A standard debt contract is assumed, implying that the interest rate is not state contingent but the default threshold is (only when firms cannot

\footnotetext{
${ }^{8}$ This structure is assumed purposefully to simplify the analysis, leaving extensions of the arrival and exit of the sudden stop for later research.
} 


\section{Optimal Monetary Policy under Sudden Stops}

fulfill their obligations will they default).

The default threshold, $\bar{\omega}_{t+1}(j)$, is set to the level of returns that is just enough to fulfill the debt contract obligations,

$$
\frac{\bar{\omega}_{t+1}(j) R_{Z, t+1} S_{t} Z_{t}(j)}{S_{t+1}}=R_{B, t}(j) B_{t}(j),
$$

where $R_{B, t}(j)$ is the contractual rate of the loan, set in the contract written in period $t$, and $R_{Z, t+1} S_{t} Z_{t}(j)$ the operational profits in units of domestic currency. If the idiosyncratic shock is greater than or equal to $\bar{\omega}_{t+1}(j)$, then the firm repays the loan and collects the remainder of the profits, equal to $\omega_{t+1}(j) R_{Z, t+1} S_{t} Z_{t}(j)-S_{t+1} R_{B, t}(j) B_{t}(j)$. Otherwise,

it declares default, foreign lenders pay the auditing cost and collect everything there is to collect, and the firm receives nothing. Because foreign lenders are risk neutral, their participation constraint takes the form of

$$
\begin{aligned}
R^{*} B_{t}(j)= & E_{t}\left[\left(1-F^{*}\left(\bar{\omega}_{t+1}(j)\right)\right) R_{B, t}(j) B_{t}(j)\right] \\
& +(1-\mu) E_{t}\left[\int_{0}^{\bar{\omega}_{t+1}(j)} \omega^{*} \frac{R_{Z, t+1} S_{t} Z_{t}(j)}{S_{t+1}} d F^{*}\left(\omega^{*}\right)\right],
\end{aligned}
$$

where $F^{*}(\cdot)$ denotes the distribution of $\omega_{t+1}(j)$, as perceived by foreigners. Following Cúrdia (2007), the previous expression can be rewritten as

$$
E_{t}\left[\Omega\left(\bar{\omega}_{t+1}(j) ; \kappa_{t}\right) R_{Z, t+1} \frac{S_{t}}{S_{t+1}} Z_{t}(j)\right]=R^{*} B_{t}(j)
$$




\section{Optimal Monetary Policy under Sudden Stops}

with

$$
\begin{aligned}
\Omega(\bar{\omega} ; \kappa) & \equiv \kappa\left[\Gamma\left(\frac{\bar{\omega}}{\kappa}\right)-\mu G\left(\frac{\bar{\omega}}{\kappa}\right)\right], \\
\Gamma(\bar{\omega}) & \equiv[1-F(\bar{\omega})] \bar{\omega}+\int_{0}^{\bar{\omega}} \omega d F(\omega), \\
G(\bar{\omega}) & \equiv \int_{0}^{\bar{\omega}} \omega d F(\omega),
\end{aligned}
$$

and $F(\cdot)$ denotes the actual distribution of $\omega_{t+1}, \Gamma\left(\bar{\omega}_{t}\right)$ the fraction of the operation profits used to repay the debt and $\mu G\left(\bar{\omega}_{t}\right)$ the fraction used to pay for the monitoring costs. Therefore $\Omega\left(\bar{\omega}_{t+1} ; \kappa_{t}\right)$ is the fraction of the operational profits that foreign lenders perceive that they will keep for themselves after paying the auditing costs.

Firms' cash flows, distributed as dividends to the households, are defined as

$$
\Pi_{w, t}(j) \equiv P_{w, t} Y\left(L_{t}(j), Z_{t-1}(j)\right)-W_{t} L_{t}(j)-S_{t} R_{B, t}(j) B_{t-1}(j)-N_{t}(j)
$$

or, equivalently, ${ }^{9}$

$$
\Pi_{w, t}(j)=\omega_{t}(j) R_{Z, t} S_{t-1} Z_{t-1}(j)-S_{t} R_{B, t}(j)\left(Z_{t-1}(j)-\frac{N_{t-1}(j)}{S_{t-1}}\right)-N_{t}(j)
$$

Given the state contingent nature of the optimal contract, the expected cash flow of the firm is

$$
E_{t-1} \Pi_{w, t}(j)=E_{t-1}\left\{\left[1-\Gamma\left(\bar{\omega}_{t}(j)\right)\right] R_{Z, t} S_{t-1} Z_{t-1}(j)-N_{t}(j)\right\}
$$

Firms maximize the discounted sum of cash flows,

$$
E_{0} \sum_{t=1}^{\infty} \beta^{t} \Lambda_{t} \pi_{w, t}(j),
$$

\footnotetext{
${ }^{9}$ Using the balance sheet equation and the assumption of constant returns to scale.
} 


\section{Optimal Monetary Policy under Sudden Stops}

subject to the participation constraint, (2.16), and the default threshold definition, (2.15), with respect to $Z_{t}(j), \bar{\omega}_{t}(j), R_{B, t-1}(j)$ and $N_{t}(j)$. The appropriate discount factor is given by $\beta^{t} \Lambda_{t}$, from the households problem, where $\Lambda_{t}=C_{t}^{-\sigma} / P_{t}$ is the Lagrangian multiplier of the budget constraint.

As detailed in Cúrdia (2007), all firms will take the same decisions in face of the expectations about the future. Therefore from this point onwards we can refer to the variables in aggregate terms. The aggregate level of dividends is given by

$$
\Pi_{w, t}=\left[1-\Gamma\left(\bar{\omega}_{t}\right)\right] R_{Z, t} S_{t-1} Z_{t-1}-N_{t}
$$

which is readily understood as the fraction of the operational profits that is not paid to the foreign lenders and subtracted from the net worth that is needed for financing the imported input.

The aggregate uncovered interest parity (UIP) relationship is given by

$$
R_{t} E_{t}\left[\frac{C_{t+1}^{-\sigma}}{P_{t+1}}\right]=R^{*} E_{t}\left[\frac{C_{t+1}^{-\sigma}}{P_{t+1}} \frac{S_{t+1}}{S_{t}} \lambda_{t+1}\right]
$$

which includes the risk premium term, $\lambda_{t+1}$, due to the fact that households have access to the international capital market only through leveraged firms, which might default on their debt. The risk premium term is given, in equilibrium, by

$$
\lambda_{t}=\frac{\Gamma^{\prime}\left(\bar{\omega}_{t}\right)}{E_{t-1}\left[\Omega^{\prime}\left(\bar{\omega}_{t} ; \kappa_{t-1}\right)\right]} .
$$

The aggregate operational profit of firms will, in equilibrium, be enough to pay a premium on the foreign risk free interest rate,

$$
E_{t}\left[\frac{C_{t+1}^{-\sigma}}{P_{t+1}}\left[1-\Gamma\left(\bar{\omega}_{t+1}\right)\right] R_{Z, t+1}\right]=\left(1-b_{t}\right) R^{*} E_{t}\left[\frac{C_{t+1}^{-\sigma}}{P_{t+1}} \frac{S_{t+1}}{S_{t}} \lambda_{t+1}\right],
$$




\section{Optimal Monetary Policy under Sudden Stops}

where $b_{t}$ is the leverage rate of firms, defined as $b_{t} \equiv B_{t} / Z_{t}$.

\subsection{Retail firms}

There is a continuum of size one of retail firms operating in a monopolistic competition environment. They purchase the domestic good from the representative wholesale firm, at price $P_{w, t}$, convert it at no additional cost into their own variety of the final good and sell it to both the domestic and foreign markets. There is price stickiness a la Calvo so with probability $\alpha_{p}$ each individual firm is not able to set prices in a given period. There is pricing to market with local currency pricing, so that $P_{H, t}$ denotes prices for the domestic market and $P_{H, t}^{*}$ the price in the foreign market. We assume identical elasticities for different varieties in both markets.

The preferences of the consumers for the different varieties of the domestic good are given by:

$$
Y_{t}^{i}=\left(\int_{0}^{1} Y_{t}^{i}(j)^{\frac{\eta-1}{\eta}} d j\right)^{\frac{\eta}{\eta-1}}
$$

with $\eta>1$ in order to imply elasticity of substitution above one. The demand for each variety is given by

$$
Y_{t}^{i}(j)=Y_{t}^{i}\left(\frac{P_{H, t}^{i}(j)}{P_{H, t}^{i}}\right)^{-\eta},
$$

where, in equilibrium, the market must clear and

$$
Y_{t}=C_{H, t}+C_{H, t}^{*} .
$$

The global foreign demand for domestic goods has the following form:

$$
C_{H, t}^{*}=\gamma^{*}\left(P_{H, t}^{*}\right)^{-\nu^{*}} C^{*}
$$




\section{Optimal Monetary Policy under Sudden Stops}

where $C^{*}$ is the foreign aggregate consumption level.

The problem of firm $j$ in the domestic market is

$$
\max _{\bar{P}_{H, t}(j)} E_{t} \sum_{\tau=0}^{\infty} \alpha_{p}^{\tau} \beta^{\tau} \Lambda_{t+\tau} C_{H, t+\tau}\left(\frac{\bar{P}_{H, t}(j)}{P_{H, t+\tau}}\right)^{-\eta}\left(\bar{P}_{H, t}(j)-P_{w, t+\tau}\right),
$$

with $\bar{P}_{H, t}(j)$ denoting the price set in period $t$. The first order condition is

$$
\bar{P}_{H, t}=\frac{\eta}{\eta-1} \frac{E_{t} \sum_{\tau=0}^{\infty} \alpha_{p}^{\tau} \beta^{\tau} \frac{C_{t+\tau}^{-\sigma}}{P_{t+\tau}} C_{H, t+\tau} P_{H, t+\tau}^{\eta} P_{w, t+\tau}}{E_{t} \sum_{\tau=0}^{\infty} \alpha_{p}^{\tau} \beta^{\tau} \frac{C_{t+\tau}^{-\sigma}}{P_{t+\tau}} C_{H, t+\tau} P_{H, t+\tau}^{\eta}}
$$

where I used the fact that all firms able to set a new price at time $t$ will choose exactly the same one. The aggregate domestic price index (DPI) is

$$
P_{H, t}=\left[\left(1-\alpha_{p}\right) \bar{P}_{H, t}^{1-\eta}+\alpha_{p} P_{H, t-1}^{1-\eta}\right]^{\frac{1}{1-\eta}}
$$

For the price setting in the export market we get equivalently

$$
\max _{\bar{P}_{H, t}^{*}(j)} E_{t} \sum_{\tau=0}^{\infty} \alpha_{p}^{\tau} \beta^{\tau} \Lambda_{t+\tau} C_{H, t+\tau}^{*}\left(\frac{\bar{P}_{H, t}^{*}(j)}{P_{H, t+\tau}^{*}}\right)^{-\eta}\left(S_{t+\tau} \bar{P}_{H, t}^{*}(j)-P_{w, t+\tau}\right)
$$

and note that because price is set in foreign currency, $S_{t} P_{H, t}^{*}(j)$, is the domestic currency value of each unit of exports. The first order condition is given by

$$
\bar{P}_{H, t}^{*}=\frac{\eta}{\eta-1} \frac{E_{t} \sum_{\tau=0}^{\infty} \alpha_{p}^{\tau} \beta^{\tau} \frac{C_{t+\tau}^{-\sigma}}{P_{t+\tau}} C_{H, t+\tau}^{*}\left(P_{H, t+\tau}^{*}\right)^{\eta} P_{w, t+\tau}}{E_{t} \sum_{\tau=0}^{\infty} \alpha_{p}^{\tau} \beta^{\tau} \frac{C_{t+\tau}^{-\sigma}}{P_{t+\tau}} C_{H, t+\tau}^{*}\left(P_{H, t+\tau}^{*}\right)^{\eta} S_{t+\tau}},
$$

and the aggregate price index is

$$
P_{H, t}^{*}=\left[\left(1-\alpha_{p}\right)\left(\bar{P}_{H, t}^{*}\right)^{1-\eta}+\alpha_{p}\left(P_{H, t-1}^{*}\right)^{1-\eta}\right]^{\frac{1}{1-\eta}}
$$




\section{Optimal Monetary Policy under Sudden Stops}

\subsection{Monetary policy}

The role of the monetary authority is to control the interest rate, which is a very reasonable assumption given how modern monetary policy is conducted, including in emerging markets, as suggested in Hawkins (2005). In the absence of explicit monetary aggregates, it is possible to think of this economy as in the cashless-limiting case of Woodford (2003).

There are three types of monetary policy that are considered in the analysis: optimal monetary analysis in a timeless perspective, optimal monetary analysis under a new commitment and simple policy rules. The best policy should avoid the time inconsistency problems discussed in Kydland and Prescott (1977) among many others. This is the optimal policy with commitment in a timeless perspective, as proposed in Woodford (1999). It is nevertheless worth considering as well the optimal policy under a new commitment, which is not time consistent, in order to highlight the extent to which the sudden stop affects the time inconsistency of policy. In both cases the monetary authority maximizes the welfare of the households subject to the laws of motion of the economy as described in appendix B.

Finally, several simple rules are considered, including interest rate rules,

$$
\frac{R_{t}}{R}=\left(\Pi_{t}\right)^{\phi_{\pi}}\left(\Pi_{H, t}\right)^{\phi_{\pi_{H}}}\left(\frac{S_{t}}{S_{t-1}}\right)^{\phi_{s}}\left(\frac{Y_{t}}{Y}\right)^{\phi_{y} / 4}
$$

and simple "specific targeting rules," in the terminology of Svensson and Woodford (2005). These involve the stabilization of a basket of variables, each with a given weight and can be represented as

$$
1=\left(\Pi_{t}\right)^{\phi_{\pi}}\left(\Pi_{H, t}\right)^{\phi_{\pi_{H}}}\left(\frac{S_{t}}{S_{t-1}}\right)^{\phi_{s}}\left(\frac{Y_{t}}{Y}\right)^{\phi_{y} / 4}
$$

in which, for the sake parsimony, one of the coefficients is normalized to one. 


\section{Optimal Monetary Policy under Sudden Stops}

\subsection{General equilibrium and parameter values}

The resources of this economy are determined by the budget constraint of the representative household. If we substitute out the profits from firms and making a few other manipulations we convert the budget constraint into the balance of payments $(\mathrm{BP})$ of this economy:

$$
0=S_{t} P_{H, t}^{*} C_{H, t}^{*}-S_{t} C_{F, t}-S_{t} Z_{t}-\Gamma\left(\bar{\omega}_{t}\right) R_{Z, t} S_{t-1} Z_{t-1}+S_{t} B_{t}
$$

Finally it's important to note that only relative prices are determined and therefore inflation rates and real variables shall be analyzed henceforth. In particular, more important than the nominal interest rate is the real interest rate, $R_{t}^{r} \equiv E_{t}\left[R_{t} / \Pi_{t+1}\right]$, the real return on imported inputs, $R_{Z, t}^{r} \equiv R_{Z, t} / \Pi_{t}$ and the DPI inflation, $\Pi_{H, t} \equiv P_{H, t} / P_{H, t-1}$. The relative prices are all normalized by the domestic CPI and represented by small caps: the real exchange rate, $s_{t}$, the real wage rate, $w_{t}$, the relative wholesale prices, $p_{w, t}$, the relative price of the domestic good, $p_{H, t}$, and real net worth, $n_{t} \cdot{ }^{10}$ The list of all equations using real variables is shown in appendix B.

The structural parameter values used follow closely those of Cúrdia (2007), except that some of them were set to values more stylized for easiness of analysis. All of the parameters are listed in appendix 3 and are used in all experiments except when otherwise noted. One parameter in particular is of importance here, the foreign demand price elasticity, which is set to one in the baseline scenario. This parameter is considered to be very important, in particular to the outcomes of the economy in terms of output. Therefore even though the baseline case takes this elasticity to be unity, a special parameter sensitivity of the results is discussed below.

The solution method depends on the analysis being conducted. For the simple rules

\footnotetext{
${ }^{10}$ The price of exports would be normalized by the foreign CPI but it is assumed that $P_{t}^{*}$ is constant at all times and therefore that would be a meaningless normalization.
} 


\section{Optimal Monetary Policy under Sudden Stops}

the model is log-linearized around the zero inflation steady state, which coincides with the optimal steady state. After log-linearization all variables are denoted by $\hat{x}_{t} \equiv \ln \left(x_{t} / x\right)$ with $x$ denoting the steady state value of the variable. For the optimal policy under a new commitment the solution is computed in two steps: derivation of the FOC based on the nonlinear equations, followed by log-linearization of all the equations in order to generate the solution to the rational expectations equilibrium (REE). The policy in a timeless perspective uses the linear quadratic approximation method proposed in Benigno and Woodford (2006).

\section{Optimal monetary policy}

The response of the economy to a sudden stop are thoroughly described in Cúrdia (2007) as well as the comparison of the impact of different policies in those responses. Here the object of interest is to characterize the optimal monetary policy under full commitment. Optimal behavior of the monetary authority should be considered in a framework in which the commitment is credible to the economic agents. A good way to earn the desired credibility is precisely by choosing a policy behavior that is consistent over time, conditional on the occurrence of shocks. Therefore optimal policy is characterized by the choice of paths for the variables such that they maximize the welfare of the households subject to the laws of motion of the economy and a pre-commitment constraints that enforce time consistency of policy. This is the timeless perspective described in Woodford (1999) and formalized in Benigno and Woodford (2007).

Besides a time-consistent optimal policy it is also useful to consider optimal policy under a commitment that is not time-consistent. This helps understanding the extent to which the sudden stop affects the commitment problem. Such alternative policy is labeled here as Ramsey. Therefore this section compares optimal policy with and without time consistency, keeping the flexible price equilibrium in the background, as a benchmark. The impulse 


\section{Optimal Monetary Policy under Sudden Stops}

response functions (IRF's) in these three cases are presented in figures 1 and 2. These show the responses of the economy to a misperceptions shock, in log-deviations ${ }^{11}$ relative to the scenario without shocks. ${ }^{12}$ Further notice that nominal variables in the flex-price equilibrium depend on the policy conducted and hence are not shown for lack of relevance.

According to these figures the optimal policy implies that the interest rate is initially kept relatively stable, while there is a devaluation of the domestic currency. One period after the interest rate is sharply increased and afterwards is gradually stabilized back to pre-shock levels. This policy leads to a strong contraction of consumption and output, with the latter falling by a smaller amount due to an increase in exports. Inflation initially increases but afterwards is roughly stabilized.

The first lesson from this exercise is immediate result that optimal policy is far from enforcing a fixed exchange rate regime. This is relevant because in several episodes of sudden stops the authorities tried to enforce precisely such a regime, failing in most cases and then allowing finally the currency to devalue. Instead, according to the results presented here they should immediately devalue, followed by the stabilization of the currency by increasing the interest rate, not the other way around.

The reasoning behind the optimal policy is as follows. The sudden stop is in fact a negative supply shock in that it increases the cost of acquiring inputs necessary to produce, by increasing the cost of financing it. This implies that there is a contraction in the financial account that needs to be matched by an increase in the current account. There are two options to achieve that: to increase export revenues and/or to reduce the value of imports. The option of enforcing a peg implies a substantial increase in the domestic interest rate

\footnotetext{
${ }^{11}$ All paths are multiplied by one hundred to give an interpretation of percentage deviations. The inflation and interest rates are further multiplied by four in order to yield annualized rate changes.

${ }^{12}$ For flexible prices and the optimal policy the evolution under no sudden stop shock is just the steady state itself. However, under Ramsey there is a deviation from steady state in the initial period even in the absence of any shocks. This is due to the time inconsistency of the policy, which is not consistent with the steady state.
} 


\section{Optimal Monetary Policy under Sudden Stops}

(unless there are vast amounts of currency reserves, which is not considered here) but that will imply a strong contraction in domestic demand. A better policy is to use both options and contract the value of imports at the same time that the revenues from exports are increased. This is precisely what the optimal policy accomplishes.

Another interesting lesson is that the comparison to the flex-price equilibrium shows that the output gap is negative on impact but persistently positive afterwards. This is consistent with the idea that optimal policy implements some smoothing of the output, relative to the flex-price equilibrium. This translates also into some smoothing of domestic consumption, especially consumption of domestic goods.

This result regarding the path of the interest rate also compares to the work of Braggion et al. (2005). They present a model in which the optimal response to reduced access to the international capital markets is an initial sharp rise in the interest rate followed by a fall to below pre-crisis levels. The reason why in their results the interest rate falls to levels below pre-crisis levels is explained by the fact that the increased requirements for collateral are permanent and therefore the interest rate needs to move to a permanent lower level to discourage borrowing and make the collateral constraint marginally not binding in the new steady state. Instead, here the misperceptions are expected to eventually revert to normal levels and therefore there is no need to make such permanent changes in the interest rate, so that it converges back to the pre-crisis levels. However it is interesting to note that after the spike the interest rates do indeed reach levels lower than the no shock scenario and converge from below. The remainder difference that requires some interpretation is the initial response of the interest rate. They get an optimal immediate increase while here it is kept low. The answer to this is in the parameter configuration. Figure 3 shows responses when $\alpha_{p}=0.5$ (instead of $\alpha_{p}=0.75$ ), hence implying smaller nominal rigidities. Figure 4 shows responses when the the foreign elasticity of foreign demand is lower with, $\nu^{*}=0.6\left(\right.$ instead of $\left.\nu^{*}=1\right)$.

If nominal rigidities are lower or if the elasticity of foreign demand is lower then both the 


\section{Optimal Monetary Policy under Sudden Stops}

nominal and real interest rates will spike on impact and then follow a gradual reduction, much like in the baseline scenario (including eventually attaining levels below pre-crisis levels and converging to those levels from below). Noticeably the lower elasticity of foreign demand is considered by some as more realistic for emerging markets (e.g. Reinhart (1994)). Therefore it can be concluded that the results in this model can be considered consistent with those in Braggion et al. (2005).

Looking more closely at these alternative parameterizations we can further conclude that as nominal rigidities are smaller or the elasticity of foreign demand is lower the emphasis is less on the depreciation and more on the impact increase of the interest rate. Regarding the smaller nominal rigidities that ought to be expected given that as the economy gets closer to flexible prices the prices do more of the adjustment towards the required real exchange rate depreciation that is needed and therefore less adjustment in the nominal exchange rate is needed.

The only reason why there is a devaluation of the currency is that it implies higher value of the export revenues. The cost however is that it also increases the cost of imported inputs, creating pressure on costs. Furthermore, it will have also a direct impact on the desired price of exports (set in local currency). If desired lower prices in exports are introduced then there is an increase in foreign demand for the domestic goods, which will lead to higher labor demand and wage pressure. This compounds to generate higher marginal costs and a higher desired prices also in the domestic retail price of the domestic good which will have the negative impact of driving lower consumption of the domestic goods and overall consumption. This mechanism is actually very important for other results but in particular it explains why higher nominal rigidities lead to stronger depreciation rates of the currency. If nominal rigidities are stronger then the transmission from desired prices to actual prices is smaller and therefore the cost of a devaluation is smaller.

It also explains why the elasticity of foreign demand influences the optimal policy. If the 


\section{Optimal Monetary Policy under Sudden Stops}

elasticity is lower then foreign demand will not react as much to the lower foreign prices and therefore the cost of the devaluation will be lower. However the benefit of the depreciation falls too because this strategy actually implies a fall in revenue in foreign currency (given that the price of exports falls more than the exports' demand increases), so that a bigger depreciation would be needed to attain the same goal. Figure 4 shows that the this reduction in benefits is more prevalent than the reduction in costs, hence the smaller devaluation. The reason is that the reduction in benefits is not one to one with that in benefits, precisely due to nominal rigidities at the level of export price determination. It can be shown that if nominal rigidities are not present in the export sector then a reduction in foreign demand elasticity promotes a bigger devaluation in response to the sudden stop.

It is also relevant to understand to what extent the sudden stop influences the time inconsistency problem. For that we can turn again to figure 1 and compare the responses between the optimal policy and Ramsey. The difference between is immediately obvious: Ramsey implies a much stronger devaluation on impact and much lower interest rates. Indeed this policy manages to increase the value of exports by so much that there is no need to impose a contraction on domestic consumption of the domestic goods. It actually increases so that the consumption basket is actually roughly stabilized. It is also noticeable that in this case output, on impact actually increases. Given that the difference between Ramsey and optimal policy increases we can conclude that the sudden stop generates an even stronger time inconsistency in policy. The reason for this goes back to the benefits and costs of a devaluation. The cost is determined by the extent to which the desired price changes are translated into actual price changes and the time inconsistency emerges from the fact that by not taking into account how past expectations were formed, the Ramsey policy exploits this to the extreme. The time consistent optimal policy instead does not exploit it as much

precisely due to the commitment to take into account past expectations about current policy behavior. 


\section{Optimal Monetary Policy under Sudden Stops}

If we eliminate the nominal rigidities in the foreign export sector (but keep the ones in the domestic retail sector) we get responses as in figure 5. It shows that the elimination of this type of rigidities leads to a bigger cost of devaluing, so that Ramsey exploits is much less. Curiously the optimal policy implies a slightly stronger devaluation which might be explained by the fact that it is less constrained by past expectations. The overall results is that the time inconsistency, measured loosely as the difference between these two policies is reduced. It is thus very reasonable to conclude that a key driver of why the sudden stop increases the time inconsistency of policy is due to the existence of nominal rigidities in the export sector.

\section{Simple rules}

In the literature monetary policy is frequently represented as following simple rules, the most prominent of which is the Taylor rule presented in Taylor (1993). Such rules stipulate that the monetary authority commits to follow a simple rule. Taylor showed that an empirical rule in which the interest rate responds to inflation and the output deviations from trend is a very good representation of how the US Federal Reserve conducted policy over a period in which monetary policy is generally considered to have done a good job. This however is an empirical statement. Nothing is said about the optimality of such rules. However they are very attractive especially in cases in which monetary policy is not very credible and therefore the monitoring of the compliance to such a simple policy can be tracked by the economic agents. Therefore the obvious question is how well do simple rules perform, relative to the

optimal policy, from a welfare perspective. A second issue is the possibility that a simple rule might actually implement the optimal policy or, at least, get very close to the optimal policy. These are precisely the two issues discussed in this section. 


\section{Optimal Monetary Policy under Sudden Stops}

\subsection{Benchmark rules}

The first question that should be posed whenever a simple rule is proposed is how good such a rule is. That will generally depend on the economic structure taking into consideration all the types of shocks that the economy faces. Here the exercise is not so much the discussion of whether such policies are the best to implement in the type of economies under consideration, but a narrower one: how good are those policies in the event of a sudden stop. Furthermore how do different types of rules compare relative to each other, from a welfare perspective.

Cook (2004) analyzes a similar question by comparing the volatility of some key variables under alternative policy rules. The conclusion is that a peg is more stabilizing than interest rate rules targeting inflation. Devereux et al. (2006) compare both the volatility of responses as well as the expected welfare and conclude that it is best to have a policy rule in terms of non-traded goods inflation or in terms of CPI, depending on the pass-through but in any case either of those fares better than an exchange rate peg. Céspedes et al. (2004) and Gertler et al. (2003) perform similar exercises in terms of a response to the foreign interest rate and also conclude that the peg is the worst policy in terms of stabilization of the economy. This section performs a welfare comparison of rules based on the quadratic approximation suggested in Benigno and Woodford (2006).

The rules considered here are those discussed in Cúrdia (2007), starting with a fixed exchange rate regime, or peg, which all of the above authors consider. Two other obvious rules are strict inflation stabilization in terms of the CPI and in terms of the DPI. Another type of rules usually considered in the literature (e.g. Gertler et al. (2003)) is a Taylor rule reacting to inflation and output deviations from steady state. This section considers two such rules, one with CPI inflation (labeled CPI Taylor) and another with DPI inflation (labeled DPI Taylor). In both of these the coefficient on inflation is 2 and the coefficient on 


\section{Optimal Monetary Policy under Sudden Stops}

output is 0.75. Like in Cook (2004) we also consider rules in which the interest rate further reacts to directly to the exchange rate, besides the implicit reaction through the inflation measure. The resulting rules are the CPI dirty float and the DPI dirty float, to convey precisely the idea that these are flexible exchange rate regimes but in which policy pays explicit attention to the exchange rate. In both the coefficient on nominal exchange rate depreciation is 0.5 . The resulting welfare comparison is shown in table 4 . The first column indicates welfare relative to the level attained by the optimal policy. A value of zero is not readily interpretable but allows us to rank how well the different policies.

The numbers suggest that the peg is the worst policy among the ones considered and that a DPI Taylor rule is the best of these ones. The welfare level of the peg is not especially relevant because we will not know if attaining $78.8 \%$ of the welfare achieved by the optimal policy is a high number or not. However, being the worst policy it allows us to compare the other rules in terms of how much welfare gap between the optimal policy and the peg they are able to close, which is precisely the measure presented in the second column of the table. This allows us to say the DPI Taylor closes about $90.2 \%$ of that welfare gap and hence we can say that it improves considerably relative to the peg. The CPI Taylor is also a good policy relative to the peg but not as much as the DPI Taylor. It is also interesting to notice that in this calibration the two dirty float rules lead to lower welfare values than the corresponding Taylor rules without reaction to the exchange rate.

The analysis can be further complemented by a comparison of these two rules (the worst

and the best out of these ones) with the optimal policy, presented in figure 6 . It becomes clear that the peg is not similar to the optimal responses implying double the contraction in output and almost double the contraction in consumption as the optimal policy. The interest rate and real exchange rate are also somewhat different, with the peg implying a more significant increase in interest rate and a smaller real depreciation. The DPI Taylor rule instead implies paths for the variables that are very similar to those implied by the 


\section{Optimal Monetary Policy under Sudden Stops}

optimal policy both in terms of the pattern but also quantitatively.

It is important to understand the extent to which the ranking changes for different parameterizations. Therefore three scenarios are considered, much like those considered in the previous section: lower nominal rigidities $\left(\alpha_{p}=0.5\right.$ in both domestic retail and export sectors), no nominal rigidities in the export sector and two different elasticities of foreign demand $\left(\nu^{*}=0.6\right.$ and $\left.\nu^{*}=20\right)$. Table 5 presents the relative welfare in all of these scenarios for each rule. The first result worth mentioning is that the peg is not always the worst policy. In particular, if the nominal rigidities in both sectors are lower or if the elasticity of foreign demand is very high then the it can become the best of these simple rules.

The performance of the peg should not be a surprise. With nominal rigidities, if a peg is enforced then the economy cannot adjust very much to the shock, except by giving time for prices to adjust as larger and larger fractions of firms adjust their prices. As nominal rigidities get smaller so does the time it takes the prices to perform this adjustment. However if the exchange rate is free to change then the adjustment will be much faster. Therefore lower nominal rigidities should eliminate a big part of the drawbacks of the peg. ${ }^{13}$ Given that these are not unreasonable parameterizations the peg should not be eliminated from the list of possible monetary policy strategies to consider when addressing a sudden stop event.

Furthermore, as the foreign demand elasticity increases a fall in the price of exports gets more power, so that a lower devaluation is necessary to accomplish an increase in foreign demand. In the limit the exchange rate is very close to being stabilized because it is not required to expand exports. It is also interesting to notice that the ranking of the peg is even worse if we consider the more realistic scenario of low elasticity of foreign demand. Another interesting result is that if nominal rigidities in exports are eliminated then the best of these rules is to stabilize the DPI price index.

\footnotetext{
${ }^{13}$ This does not mean that it implements the optimal policy in those alternative scenarios or even that it is the best simple rule (which shall be analyzed later). It simply states that the peg performs relatively better than several alternative simple rules.
} 


\section{Optimal Monetary Policy under Sudden Stops}

One final comment is that under lower nominal rigidities the peg is the best rule but the CPI dirty float is also fairly good, so it is possible that in this scenario a dirty float with different coefficients might do better than a pure peg. In the scenario of lower (and more realistic) elasticity of foreign demand the DPI dirty float is actually the highest ranked policy which suggests that a dirty float might do a reasonably good job in the event of a sudden stop.

\subsection{Optimal rules}

Comparison of simple rules among themselves and with the optimal policy is an informative exercise, but it can be subject to the criticism of why certain coefficients are used instead of others, and whether these influence the results. Therefore we now discuss which are the best simple rules within a certain class of rules.

The first class of rules considered is the one in which the interest rate reacts to CPI inflation, output and the exchange rate:

$$
\frac{R_{t}}{R}=\left(\Pi_{t}\right)^{\phi_{\pi}}\left(\frac{S_{t}}{S_{t-1}}\right)^{\phi_{s}}\left(\frac{Y_{t}}{Y}\right)^{\phi_{y} / 4}
$$

The first immediate result is that it is optimal to set $\phi_{s}=0$, hence the interest rate should not react to the exchange rate more than what is already implied by the CPI. ${ }^{14}$ This however is the optimal coefficient if we restrict it to be non-negative. Without this restriction it is optimal to react to the exchange rate less than the implied by reacting to CPI inflation (a negative coefficient $\left.\phi_{s}\right)$.

The search for the best coefficients for inflation and output shows that if both diverge to infinity at a constant ratio then the welfare keeps increasing. This is not a very reasonable rule to implement and it actually suggests that a better policy is to target a combination of

\footnotetext{
${ }^{14}$ To better understand this statement, just recall that $P_{t}=P_{H, t}^{\gamma} S_{t}^{1-\gamma}$.
} 


\section{Optimal Monetary Policy under Sudden Stops}

inflation and output stabilization, implied by

$$
1=\left(\Pi_{t}\right)^{\phi_{\pi}}\left(\frac{Y_{t}}{Y}\right)^{\phi_{y} / 4} .
$$

If we normalize $\phi_{\pi}=1$ then the optimal weight on output is $\phi_{y}=3.516$, which implies that a one annual percentage point inflation has the same weight as a 0.28 percentage point output deviation from steady state levels in the targeting basket. Such policy closes about $85.38 \%$ of the welfare gap between the peg and the optimal policy. This is an improvement relative to the benchmark CPI Taylor rule but still lower than the welfare levels of the benchmark DPI interest rate rule.

If we consider rules reacting to CPI inflation and output, but now in terms of the quarterly changes in the output, instead of deviations from steady state we are able to improve on the previous one. The best such rule is an interest rate rule

$$
\frac{R_{t}}{R}=\left(\Pi_{t}\right)^{5.53}\left(\frac{Y_{t}}{Y_{t-1}}\right)^{6.94}
$$

which implies fairly strong interest rate responses to changes in either the inflation rate or the output growth rate. Such a rule closes $95.31 \%$ of the welfare gap between the peg and the optimal policy, which is an improvement relative to the CPI Taylor consider before.

Another relevant case is the one in which we consider DPI inflation, exchange rate depreciation rate and output deviations from steady state,

$$
1=\left(\Pi_{H, t}\right)\left(\frac{S_{t}}{S_{t-1}}\right)^{\phi_{s}}\left(\frac{Y_{t}}{Y}\right)^{\phi_{y} / 4} .
$$

This is relevant because we allow for the differentiated response to DPI inflation and exchange rate, without restricting to the weights implied in the consumption basket and the comparison of the benchmark rules suggests that a rule based on DPI instead of CPI per- 


\section{Optimal Monetary Policy under Sudden Stops}

forms better. The best interest rate rule again implies coefficients diverging to infinity at constant rates. The best targeting rule, seen also as the limit of the best interest rate rule is to set $\phi_{s}=0.062$ and $\phi_{y}=1.511$, which implies that one annual percentage point inflation has the same weight as a $4 \%$ quarterly exchange rate depreciation or a $0.66 \%$ deviation of the output from steady state. Given the big volatility of exchange rates this is a significant reaction to the exchange rate, but it is not as much as implied by the CPI (which would be $(1-\gamma) / \gamma=0.33)$. Indeed if this rule was converted to CPI targeting rule it would imply a negative weight for the exchange rate.

This rule closes $98.13 \%$ the gap between the peg and the optimal policy. This means that even though it doesn't exactly implement the optimal policy it gets really close. This is confirmed by a comparison of the impulse response functions presented in figure 7 . The two responses are almost identical for all real variables. The nominal ones are somewhat more different. It should be noted that all the other rules considered yielded lower levels of welfare than this one for the baseline scenario.

Given the optimal simple rule it is important to understand to what extent it is sensitive to some key parameters of this economy. If we consider lower nominal rigidities $\left(\alpha_{p}=0.5\right)$ in both the export and domestic retail markets then it is optimal to target a combination of exchange rate depreciation and output deviations from steady state,

$$
1=\left(\frac{S_{t}}{S_{t-1}}\right)\left(\frac{Y_{t}}{Y}\right)^{1.84}
$$

which confirms the previous result that as nominal rigidities are smaller it is better to stabilize the exchange rate. However it should be a flexible stabilization, with some weight given to output deviations from steady state. This flexible criterion improves somewhat on the peg (which is considered above the best of the benchmark rules), closing $76.9 \%$ of the welfare gap between DPI stabilization (the worst rule considered) and the optimal policy. This rule 


\section{Optimal Monetary Policy under Sudden Stops}

however implies responses to the shock that are different from those implied by the optimal policy.

If we consider that there are no nominal rigidities in the export sector then the best simple rule within the class considered here is to impose DPI stabilization.

Previously we had mentioned that as the elasticity of foreign demand increases the peg becomes a better policy. similarly if we consider the smaller elasticity of foreign demand that might be somewhat more realistic, then the optimal simple rule considered is a flexible targeting criterion of the type considered for the benchmark scenario but in which the coefficients are different: $\phi_{s}=0.426$ and $\phi_{y}=3.583$. In this scenario of low elasticity the worst rule considered is DPI stabilization and the optimal rule closes the welfare gap between that and the optimal policy is $97.8 \%$, implying that it is a very good policy indeed even if it does not exactly implement the optimal policy. Furthermore we can formulate this rule as one in terms of flexible targeting of CPI, with weights in the exchange rate and output:

$$
1=\Pi_{t}\left(\frac{S_{t}}{S_{t-1}}\right)^{0.132}\left(\frac{Y_{t}}{Y}\right)^{0.671}
$$

It is noteworthy that if the elasticity of foreign demand is lower then the exchange rate depreciation gains more weight in the targeting rule, above that implied by the CPI basket, hence the positive coefficient above.

The conclusion is that for reasonable parameter configurations the best simple rule is to follow a flexible inflation targeting rule, with some weight on output deviations from steady state and a weight on the exchange rate relative to the domestic prices that may or may not be below that implied by the CPI basket. In any case this is very simple rule that does not implement the optimal policy but gets really close to achieve that. 


\section{Optimal Monetary Policy under Sudden Stops}

\section{Conclusion}

This paper considered a versatile framework that is reasonable to describe an emerging market and performed comprehensive analysis of optimal monetary policy in response to a sudden stop in capital inflows.

Optimal monetary policy exploits the export revenues in order to minimize the impact on the domestic economy but the recession is not totally avoided. A domestic currency depreciation is combined with high interest rates to achieve this result. Unless there are no nominal rigidities in the export sector, the arrival of the sudden stop increases the problem of time inconsistency of policy, further strengthening the importance of credibility and commitment for emerging markets.

In a comparison of the optimal policy with simple rules, we conclude that, for the relevant parameterizations, the optimal policy is fairly well approximated by a flexible targeting rule, in which a combination of domestic prices, exchange rate and output are considered. However, the weights on the different variables are sensitive to parametrization in a nonnegligible way.

An important outcome of the paper is to show that whether a fixed exchange rate regime is a good policy depends on the economic environment (or in the model, on the parametrization). For the benchmark parametrization, the peg performs badly, from a welfare perspective. If we consider lower nominal rigidities or high elasticity of foreign demand, then the peg performs much better.

The analysis presented here is fairly broad but it does not close the subject of optimal policy in an emerging market subject to sudden stops. A relevant limitation of it is the consideration of the shock to be completely exogenous. Actually most papers on the matter are subject to this criticism and it would be important to analyze the case in which the arrival of the sudden stop is not exogenous or in which policy can influence the duration of 


\section{Optimal Monetary Policy under Sudden Stops}

such episodes. Caballero and Krishnamurthy (2005) discuss the consequences for monetary policy of the threat of a sudden stop that can occur in the future and how current and future expected policies interact. This type of exercise should be extended further to incorporate more complete frameworks such as the one considered here.

\section{References}

Backus, D., Routledge, B., and Zin, S. (2004). Exotic preferences for macroeconomists. In Gertler, M. and Rogoff, K., editors, NBER Macroeconomics Annual 2004, chapter 5, pages 319-390. The MIT Press, Cambridge.

Benigno, P. and Woodford, M. (2006). Optimal inflation targeting under alternative fiscal regimes. NBER Working Paper No. 12158.

Benigno, P. and Woodford, M. (2007). Linear-quadratic approximation of optimal policy problems. Mimeo.

Bernanke, B. and Gertler, M. (1989). Agency costs, net worth and business fluctuations. American Economic Review, 79(1):14-31.

Bernanke, B. S., Gertler, M., and Gilchrist, S. (1999). The financial accelerator in a quantitative business cycle framework. In Taylor, J. B. and Woodford, M., editors, Handbook of Macroeconomics, volume 1C, chapter 21, pages 1341-93. North-Holland, Amsterdam.

Braggion, F., Christiano, L. J., and Roldos, J. (2005). Optimal monetary policy in a "sudden stop". Mimeo.

Caballero, R. J. (2001). Macroeconomic Volatility in Reformed Latin America, Diagnosis and Policy Proposals. Inter-American Development Bank, Washington, D.C. 


\section{Optimal Monetary Policy under Sudden Stops}

Caballero, R. J. and Krishnamurthy, A. (2005). Inflation targeting and sudden stops. In Bernanke, B. S. and Woodford, M., editors, The Inflation-Targeting Debate, chapter 10. The University of Chicago Press, Chicago.

Calvo, G. A. (1998). Capital flows and capital-markets crises: The simple economics of sudden stops. Journal of Applied Economics, 1(1):35-54.

Calvo, G. A. and Reinhart, C. M. (2000). When capital inflows come to a sudden stop: Consequences and policy options. In Kenen, P. and Swoboda, A., editors, Key Issues in Reform of the International Monetary and Financial System, pages 175-201. International Monetary Fund, Washington DC.

Céspedes, L. F., Chang, R., and Velasco, A. (2004). Balance sheets and exchange rate policy. American Economic Review, 94(4):1183-1193.

Cook, D. (2004). Monetary policy in emerging markets: Can liability dollarization explain contractionary devaluations? Journal of Monetary Economics, 51(6):1155-1181.

Cúrdia, V. (2007). Monetary policy under sudden stops. Federal Reserve Bank of New York Staff Report No. 278.

Devereux, M. B., Lane, P. R., and Xu, J. (2006). Exchange rates and monetary policy in emerging market economies. The Economic Journal, 116(511):478-506.

Fraga, A., Goldfajn, I., and Minella, A. (2003). Inflation targeting in emerging market economies. NBER Working Paper No. 10019.

Gertler, M., Gilchrist, S., and Natalucci, F. M. (2003). External constraints on monetary policy and the financial accelerator. BIS Working Paper 139.

Gilboa, I. and Schmeidler, D. (1989). Maxmin expected utility with non-unique prior. Journal of Mathematical Economics, 18(2):141-53. 


\section{Optimal Monetary Policy under Sudden Stops}

Hawkins, J. (2005). Globalisation and monetary operations in emerging economies. In Globalisation and Monetary Policy in Emerging Markets, pages 59-80. BIS Papers No 23.

Hevia, C. (2006). Optimal policy with 'sudden stops'. Mimeo.

Kydland, F. E. and Prescott, E. C. (1977). Rules rather than discretion: The inconsistency of optimal plans. Journal of Political Economy, 85(3):473-492.

Mishkin, F. S. (2000). Inflation targeting in emerging-market countries. American Economic Review, 90(2):105-109.

Mishkin, F. S. and Savastano, M. A. (2002). Monetary policy strategies for emerging market countries: Lessons from latin america. Comparative Economic Studies, 44(2/3):45-82.

Reinhart, C. M. (1994). Devaluation, relative prices, and international trade: Evidence from developing countries. IMF Working Paper No. 94/140.

Svensson, L. E. O. and Woodford, M. (2005). Implementing optimal policy through inflationforecast targeting. In Bernanke, B. and Woodford, M. S., editors, The Inflation-Targeting Debate. University of Chicago Press, Chicago.

Taylor, J. B. (1993). Discretion versus policy rules in practice. Carnegie-Rochester Conference Series on Public Policy, 39:195-214.

Woodford, M. (1999). Commentary: How should monetary policy be conducted in an era of price stability? In New Challenges for Monetary Policy. Federal Reserve of Kansas City, Kansas City.

Woodford, M. (2003). Interest and Prices. Princeton University Press, Princeton. 
Optimal Monetary Policy under Sudden Stops

\section{A Variables and parameters}

Table 1: Variables present in the model

\begin{tabular}{llll}
\hline \hline$P_{t}$ & consumption price index $(\mathrm{CPI})$ & $\Pi_{t}$ & CPI inflation rate \\
$P_{H, t}$ & domestic price index (DPI) & $\Pi_{H, t}$ & DPI inflation rate \\
$P_{H, t}^{*}$ & exports price index $(1)$ & $p_{H, t}$ & relative dom. goods retail price \\
$P_{w, t}$ & wholesale dom. goods price & $p_{w, t}$ & wholesale dom. goods relative price \\
$W_{t}$ & nominal wage rate & $w_{t}$ & real wage rate \\
$R_{t}$ & domestic interest rate & $R_{t}^{r}$ & real interest rate \\
$R^{*}$ & foreign risk free interest rate & $\lambda_{t}$ & risk premium term \\
$R_{Z, t}$ & returns on imported inputs & $R_{Z, t}^{r}$ & real returns on imported inputs \\
$S_{t}$ & nominal exchange rate & $s_{t}$ & real exchange rate \\
$C_{t}$ & consumption bundle & $C^{*}$ & foreign aggregate consumption \\
$C_{H, t}$ & consumption of domestic goods & $C_{H, t}^{*}$ & foreign consumption of dom. goods \\
$C_{F, t}$ & consumption of foreign goods & $Y_{t}$ & domestic goods production \\
$L_{t}$ & labor & $Z_{t}$ & imported inputs \\
$B_{t}$ & debt $(1)$ & $b_{t}$ & leverage ratio \\
$\omega_{t}(j)$ & imported input productivity shock & $\omega_{t}^{*}(j)$ & foreigners perceptions about $\omega_{t}(j)$ \\
$\bar{\omega}_{t}$ & default threshold & $R_{B, t}$ & gross interest rate in debt contract \\
$\pi_{r, t}$ & profits of retail firms & $\pi_{w, t}$ & profits of wholesale firms \\
$N_{t}$ & nominal net worth & $n_{t}$ & real net worth \\
$D_{t}$ & domestic assets & $\kappa_{t}$ & misperception factor \\
\hline \hline
\end{tabular}

(1) defined in foreign currency 


\section{Optimal Monetary Policy under Sudden Stops}

Table 2: Parameters present in the model

\begin{tabular}{ll}
\hline \hline$\beta$ & discount factor \\
$\sigma$ & inverse of the intertemporal elasticity of substitution \\
$\psi$ & inverse of the labor supply elasticity \\
$\gamma$ & share of the domestic good in the consumption under unit elasticity of substitution \\
$\alpha$ & share of labor to the production of the domestic goods under unit elasticity of substitution \\
$\sigma_{\omega}^{2}$ & variance of the log-normal distribution of $\omega$ \\
$\mu$ & monitoring costs \\
$\delta_{n}$ & probability of exit from sudden stop \\
$\kappa_{s s}$ & misperception factor during sudden stop \\
$\eta$ & elasticity of substitution among the different varieties of the domestic goods \\
$\nu^{*}$ & foreign demand price elasticity \\
$\gamma^{*}$ & share of the domestic good in the foreign consumption under unit elasticity of substitution \\
$\alpha_{p}$ & probability that a firm is not able to set prices in a given period \\
\hline \hline
\end{tabular}

Table 3: Parameter values

\begin{tabular}{llllllll}
\hline \hline$\beta$ & 0.98401 & $\alpha$ & 0.5 & $\nu^{*}$ & 1 & $\mu$ & 0.019065 \\
$\sigma$ & 1 & $\alpha_{p}$ & 0.75 & $\gamma^{*}$ & 0.1 & $\sigma_{\omega}$ & 0.392202 \\
$\psi$ & 2 & $\eta$ & 6 & $C^{*}$ & 5 & $\delta_{n}$ & 0.10 \\
$\gamma$ & 0.75 & & & $R^{*}$ & 1.01 & $\kappa_{s s}$ & 0.75 \\
\hline \hline
\end{tabular}


Optimal Monetary Policy under Sudden Stops

\section{B All equations describing the economy}

We can summarize all the equations of the economy:

$$
\begin{aligned}
& C_{t}^{-\sigma}=\beta E_{t}\left[C_{t+1}^{-\sigma} \frac{R_{t}}{\prod_{t+1}}\right] \\
& w_{t}=L_{t}^{\psi} C_{t}^{\sigma} \\
& C_{H, t}=\gamma \frac{C_{t}}{p_{H, t}} \\
& C_{F, t}=(1-\gamma) \frac{C_{t}}{s_{t}} \\
& 1=p_{H, t}^{\gamma} s_{t}^{1-\gamma} \\
& Y_{t}=\left(\frac{L_{t}}{\alpha}\right)^{\alpha}\left(\frac{Z_{t-1}}{1-\alpha}\right)^{1-\alpha} \\
& L_{t}=\alpha \frac{p_{w, t} Y_{t}}{w_{t}} \\
& n_{t}=\left(1-b_{t}\right) s_{t} Z_{t} \\
& B_{t}=b_{t} Z_{t} \\
& \bar{\omega}_{t}=\frac{R_{B, t-1}}{R_{Z, t}^{r}} \frac{s_{t}}{s_{t-1}} b_{t-1} \\
& E_{t}\left[\Omega\left(\bar{\omega}_{t+1} ; \kappa_{t}\right) R_{Z, t+1}^{r} \frac{s_{t}}{s_{t+1}}\right]=R^{*} b_{t} \\
& E_{t}\left[C_{t+1}^{-\sigma}\left[1-\Gamma\left(\bar{\omega}_{t+1}\right)\right] R_{Z, t+1}^{r}\right]=\left(1-b_{t}\right) E_{t}\left[C_{t+1}^{-\sigma} \frac{R_{t}}{\Pi_{t+1}}\right] \\
& E_{t}\left[C_{t+1}^{-\sigma} \frac{R_{t}}{\prod_{t+1}}\right]=E_{t}\left[C_{t+1}^{-\sigma} \lambda_{t+1} \frac{s_{t+1}}{s_{t}} R^{*}\right] \\
& \lambda_{t}=\frac{\Gamma^{\prime}\left(\bar{\omega}_{t}\right)}{E_{t}\left[\Omega^{\prime}\left(\bar{\omega}_{t+1} ; \kappa_{t}\right)\right]} \\
& R_{Z, t}^{r}=(1-\alpha) \frac{p_{w, t} Y_{t}}{s_{t-1} Z_{t-1}} \\
& Y_{t}=C_{H, t}+C_{H, t}^{*} \\
& C_{H, t}^{*}=\gamma^{*}\left(P_{H, t}^{*}\right)^{-\nu^{*}} C^{*} \\
& F_{t}=C_{t}^{-\sigma} C_{H, t} p_{H, t}^{\eta} p_{w, t}+\alpha_{p} \beta E_{t}\left[\Pi_{t+1}^{\eta} F_{t+1}\right]
\end{aligned}
$$


Optimal Monetary Policy under Sudden Stops

$$
\begin{gathered}
K_{t}=C_{t}^{-\sigma} C_{H, t} p_{H, t}^{\eta}+\alpha_{p} \beta E_{t}\left[\Pi_{t+1}^{\eta-1} K_{t+1}\right] \\
p_{H, t}=\left[\left(1-\alpha_{p}\right)\left(\frac{\eta}{\eta-1} \frac{F_{t}}{K_{t}}\right)^{1-\eta}+\alpha_{p}\left(\frac{p_{H, t-1}}{\Pi_{t}}\right)^{1-\eta}\right]^{\frac{1}{1-\eta}} \\
F_{t}^{*}=C_{t}^{-\sigma} C_{H, t}^{*}\left(P_{H, t}^{*}\right)^{\eta} p_{w, t}+\alpha_{p} \beta E_{t}\left[F_{t+1}^{*}\right] \\
K_{t}^{*}=C_{t}^{-\sigma} C_{H, t}^{*}\left(P_{H, t}^{*}\right)^{\eta} s_{t}+\alpha_{p} \beta E_{t}\left[K_{t+1}^{*}\right] \\
P_{H, t}^{*}=\left[\left(1-\alpha_{p}\right)\left(\frac{\eta}{\eta-1} \frac{F_{t}^{*}}{K_{t}^{*}}\right)^{1-\eta}+\alpha_{p}\left(P_{H, t-1}^{*}\right)^{1-\eta}\right]^{\frac{1}{1-\eta}} \\
0=s_{t} P_{H, t}^{*} C_{H, t}^{*}-s_{t} C_{F, t}-s_{t} Z_{t}-\Gamma\left(\bar{\omega}_{t}\right) R_{Z, t}^{r} s_{t-1} Z_{t-1}+b_{t} s_{t} Z_{t}
\end{gathered}
$$

Notice the addition of four artificial variables, $F_{t}, K_{t}, F_{t}^{*}$ and $K_{t}^{*}$ to allow for a recursive formulation of the DPI and the price of export goods. 
Optimal Monetary Policy under Sudden Stops

\section{Welfare ranking}

Table 4: Welfare comparison of benchmark rules

\begin{tabular}{lcc}
\hline \hline & $W / W_{\text {opt }}$ & $\frac{W-W_{\text {peg }}}{W_{\text {opt }}-W_{\text {peg }}}$ \\
\hline Peg & 0.788436 & 0 \\
CPI stabilization & 0.933456 & 0.685467 \\
DPI stabilization & 0.927364 & 0.656671 \\
CPI Taylor & 0.936369 & 0.699233 \\
DPI Taylor & 0.979336 & 0.902328 \\
CPI dirty float & 0.913253 & 0.589973 \\
DPI dirty float & 0.962173 & 0.821203 \\
\hline \hline
\end{tabular}

Table 5: Welfare comparison of benchmark rules under alternative scenarios

\begin{tabular}{lccccc}
\hline \hline$W / W_{\text {opt }}$ & benchmark & $\begin{array}{c}\text { low } \\
\text { nominal } \\
\text { rigidities }^{(1)}\end{array}$ & $\begin{array}{c}\text { no nominal } \\
\text { rigidities in } \\
\text { exports }^{(2)}\end{array}$ & $\begin{array}{c}\text { low elast. } \\
\text { foreign } \\
\text { demand }^{(3)}\end{array}$ & $\begin{array}{c}\text { high elast. } \\
\text { foreign } \\
\text { demand }^{(4)}\end{array}$ \\
\hline Peg & 0.788436 & 0.943950 & 0.749428 & 0.867168 & 0.999112 \\
CPI stabilization & 0.933456 & 0.885350 & 0.829483 & 0.961353 & 0.998578 \\
DPI stabilization & 0.927364 & 0.798439 & 0.967205 & 0.789743 & 0.986666 \\
CPI Taylor & 0.936369 & 0.899307 & 0.865398 & 0.969520 & 0.939739 \\
DPI Taylor & 0.979336 & 0.864994 & 0.950449 & 0.943635 & 0.945285 \\
CPI dirty float & 0.913253 & 0.915217 & 0.831320 & 0.977851 & 0.964824 \\
DPI dirty float & 0.962173 & 0.892011 & 0.892861 & 0.983912 & 0.963089 \\
\hline \hline
\end{tabular}

(1) $\alpha_{p}=0.5$ in both export and domestic retail sectors

(2) $\alpha_{p}=0.75$ in domestic retail sector but $\alpha_{p}=0$ in export sector

(3) $\nu^{*}=0.6$

(4) $\nu^{*}=20$ 
Optimal Monetary Policy under Sudden Stops

\section{Impulse response functions}

Figure 1: Responses under optimal policy
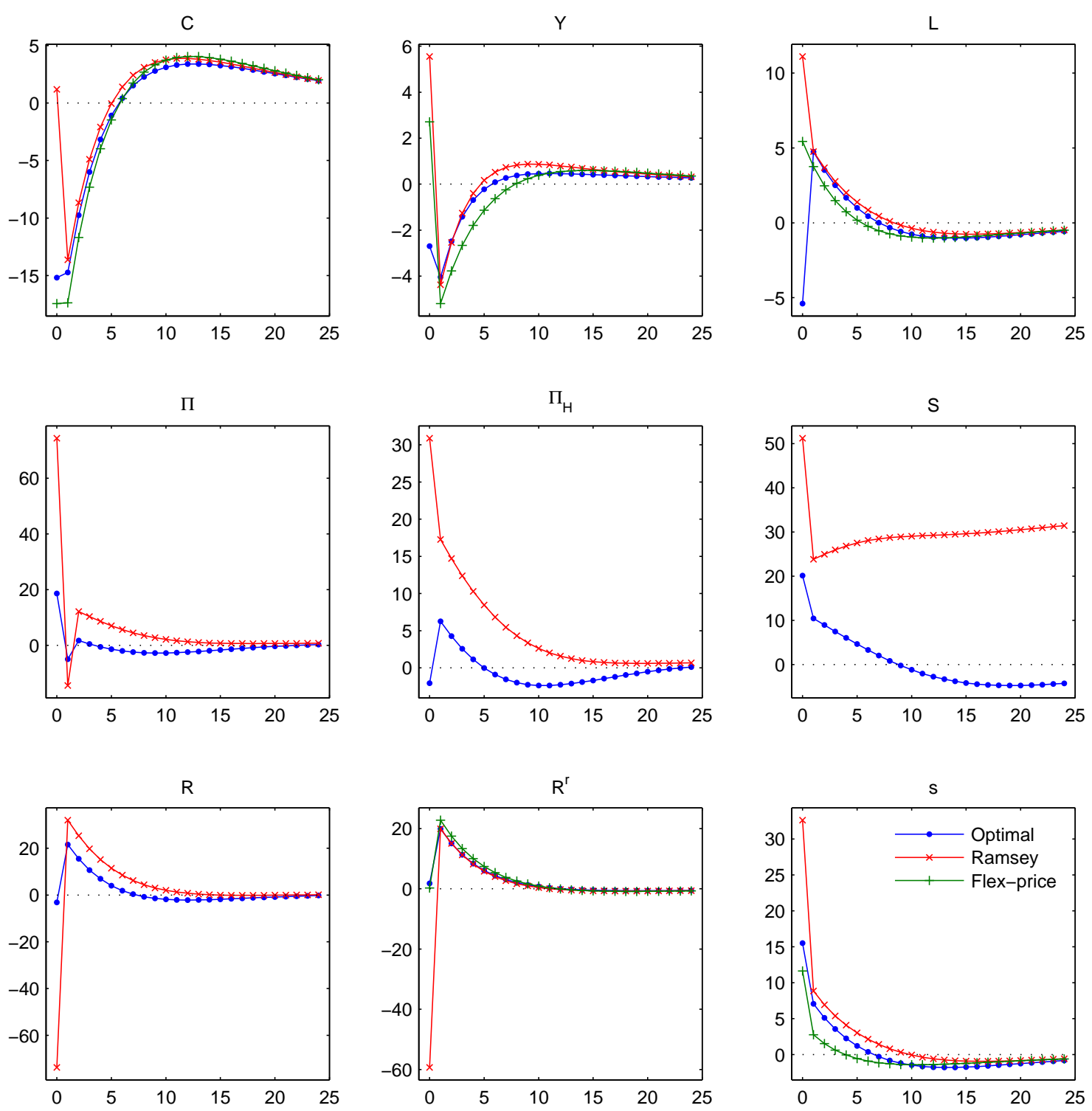


\section{Optimal Monetary Policy under Sudden Stops}

Figure 2: Responses under optimal policy (continued)
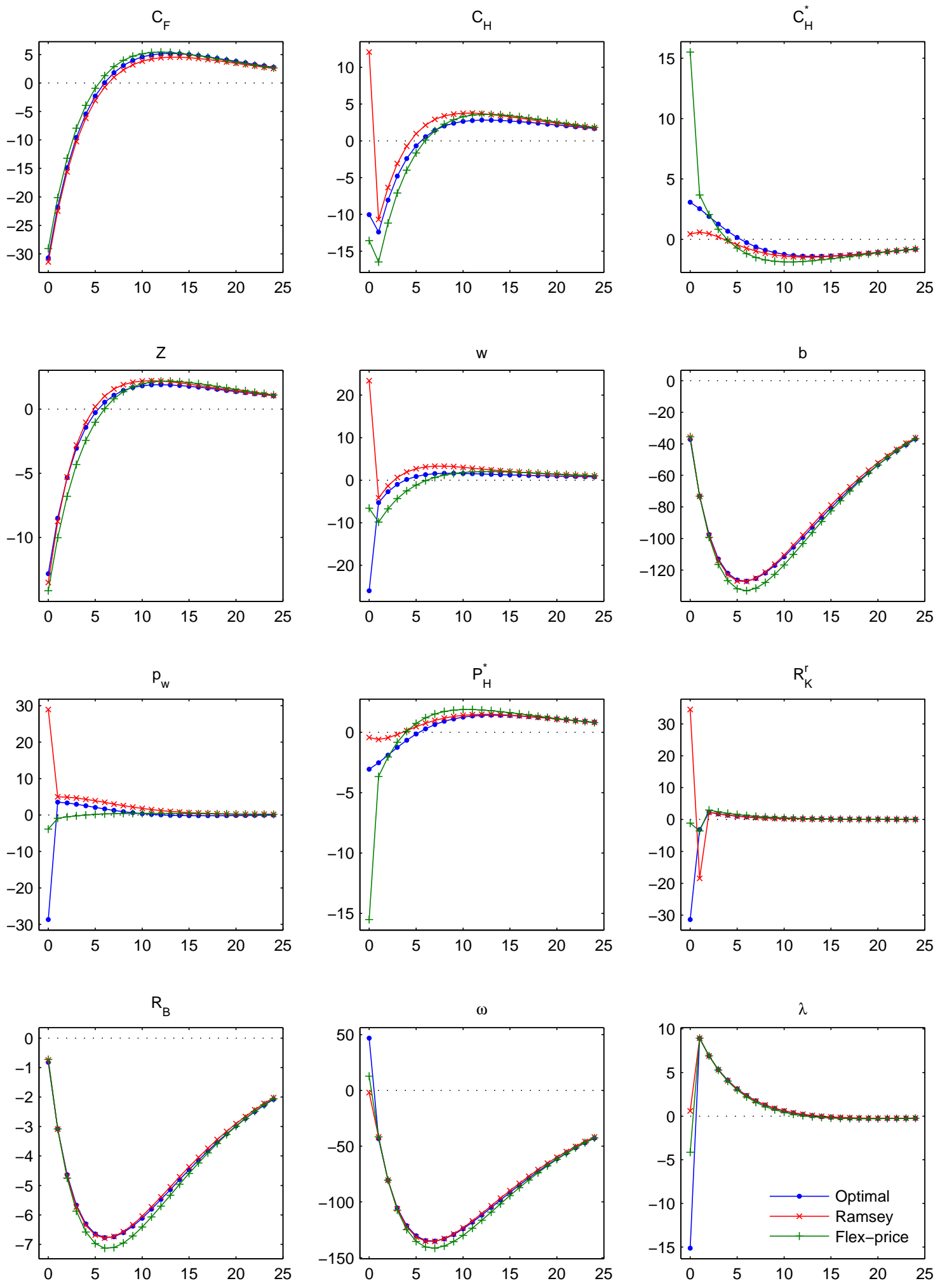


\section{Optimal Monetary Policy under Sudden Stops}

Figure 3: Responses under optimal policy with smaller nominal rigidities
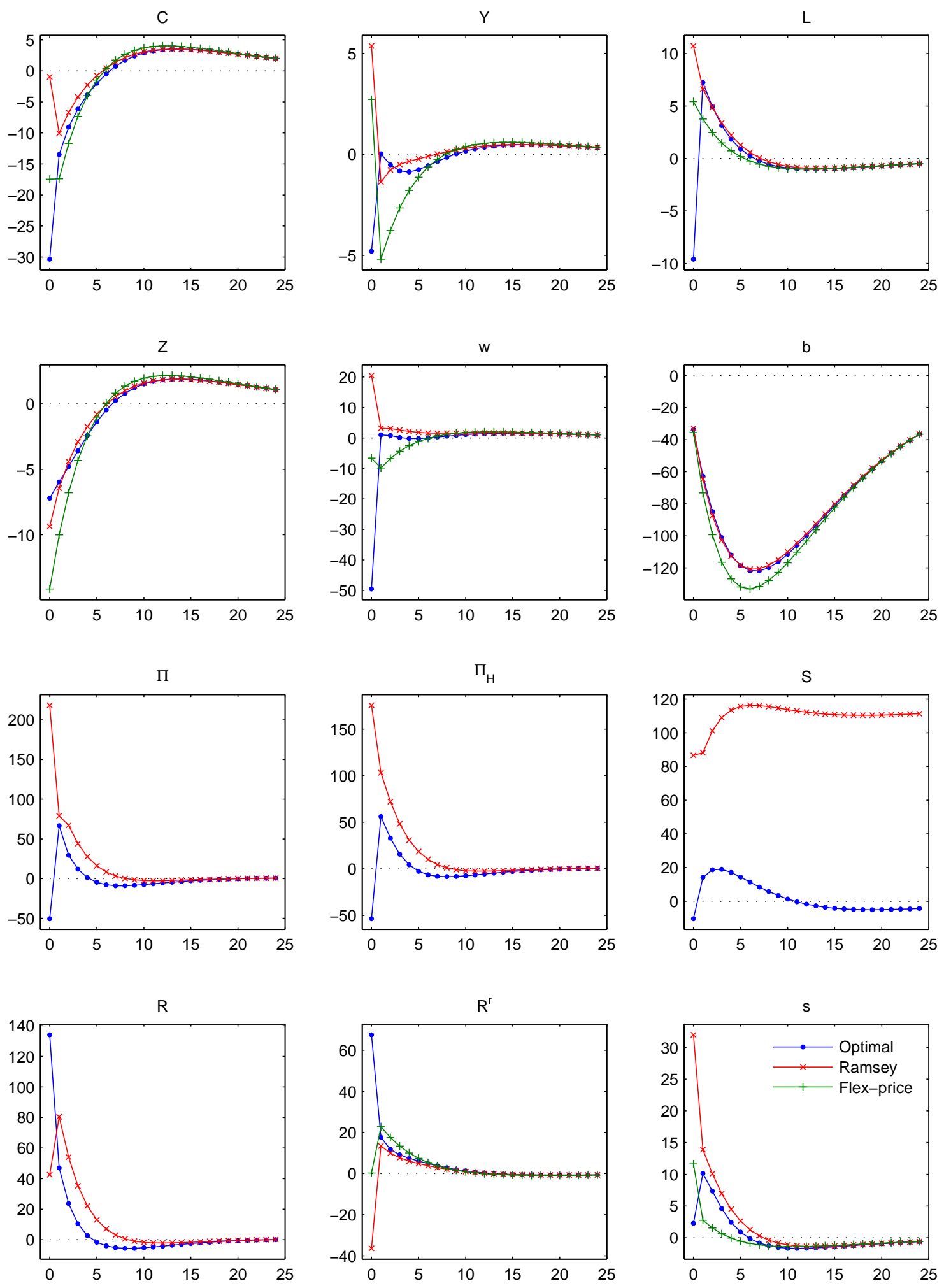


\section{Optimal Monetary Policy under Sudden Stops}

Figure 4: Responses under optimal policy with low elasticity of foreign demand
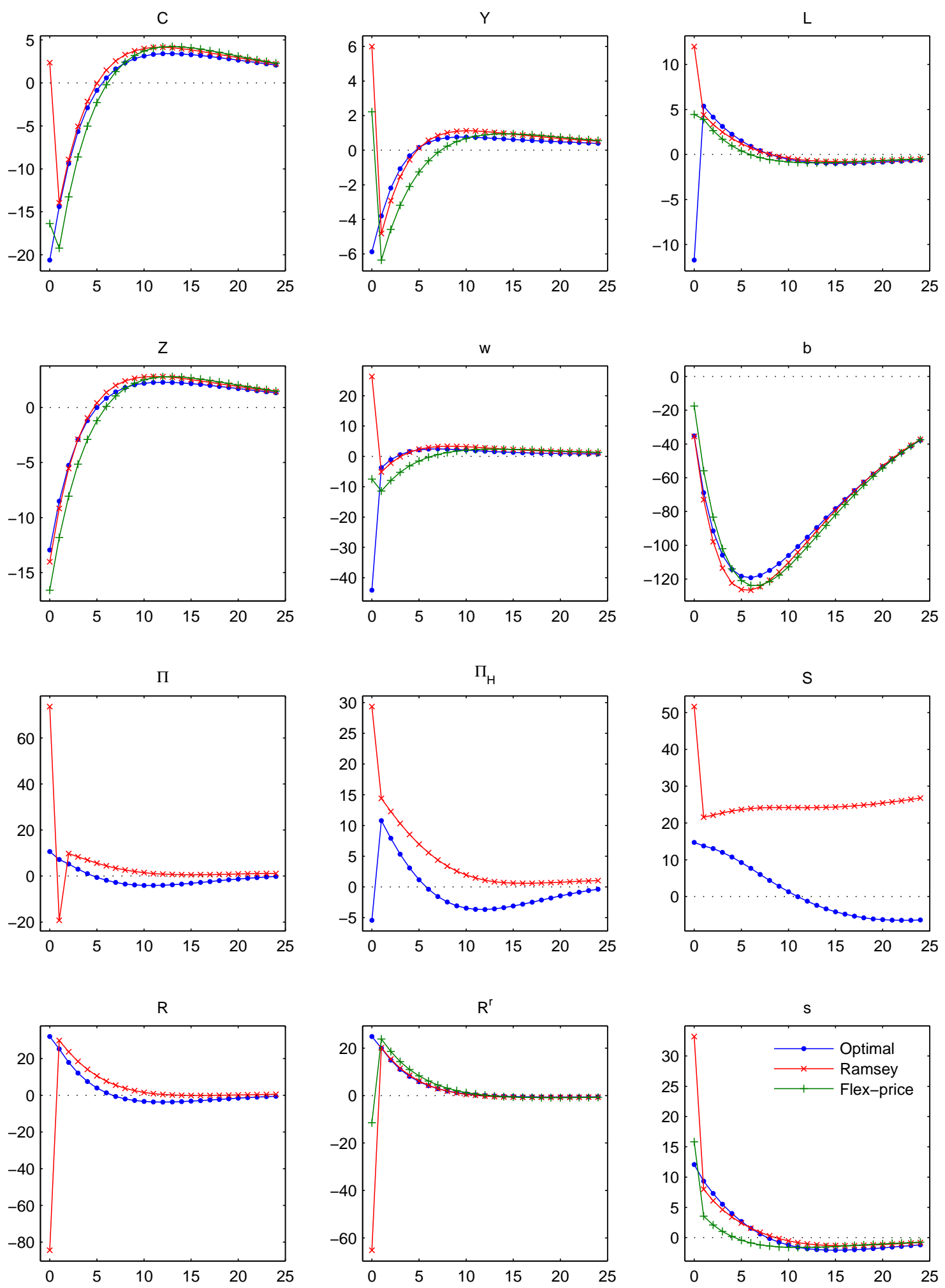


\section{Optimal Monetary Policy under Sudden Stops}

Figure 5: Responses under optimal policy without nominal rigidities in export sector
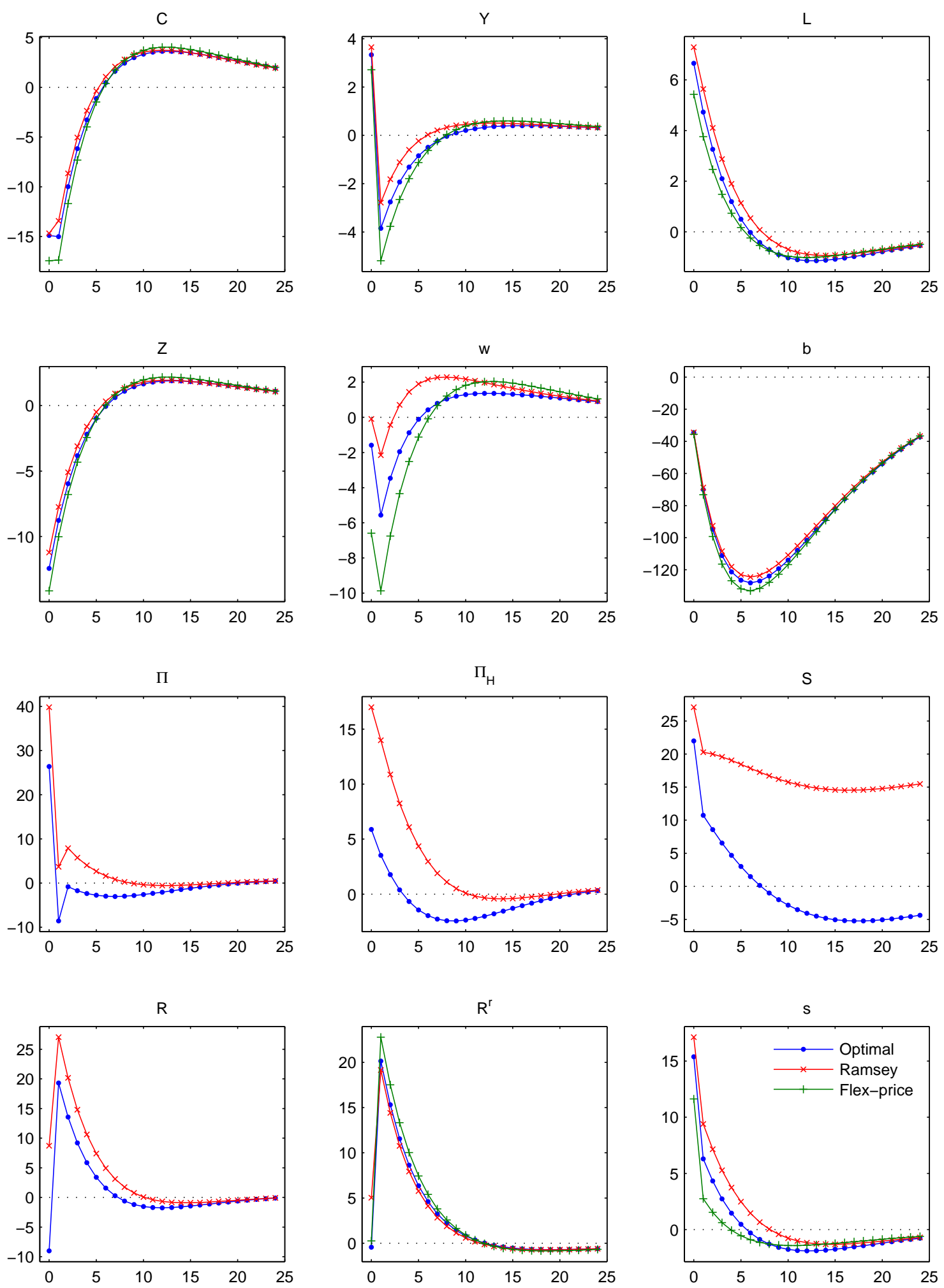


\section{Optimal Monetary Policy under Sudden Stops}

Figure 6: Responses under optimal policy and two simple rules
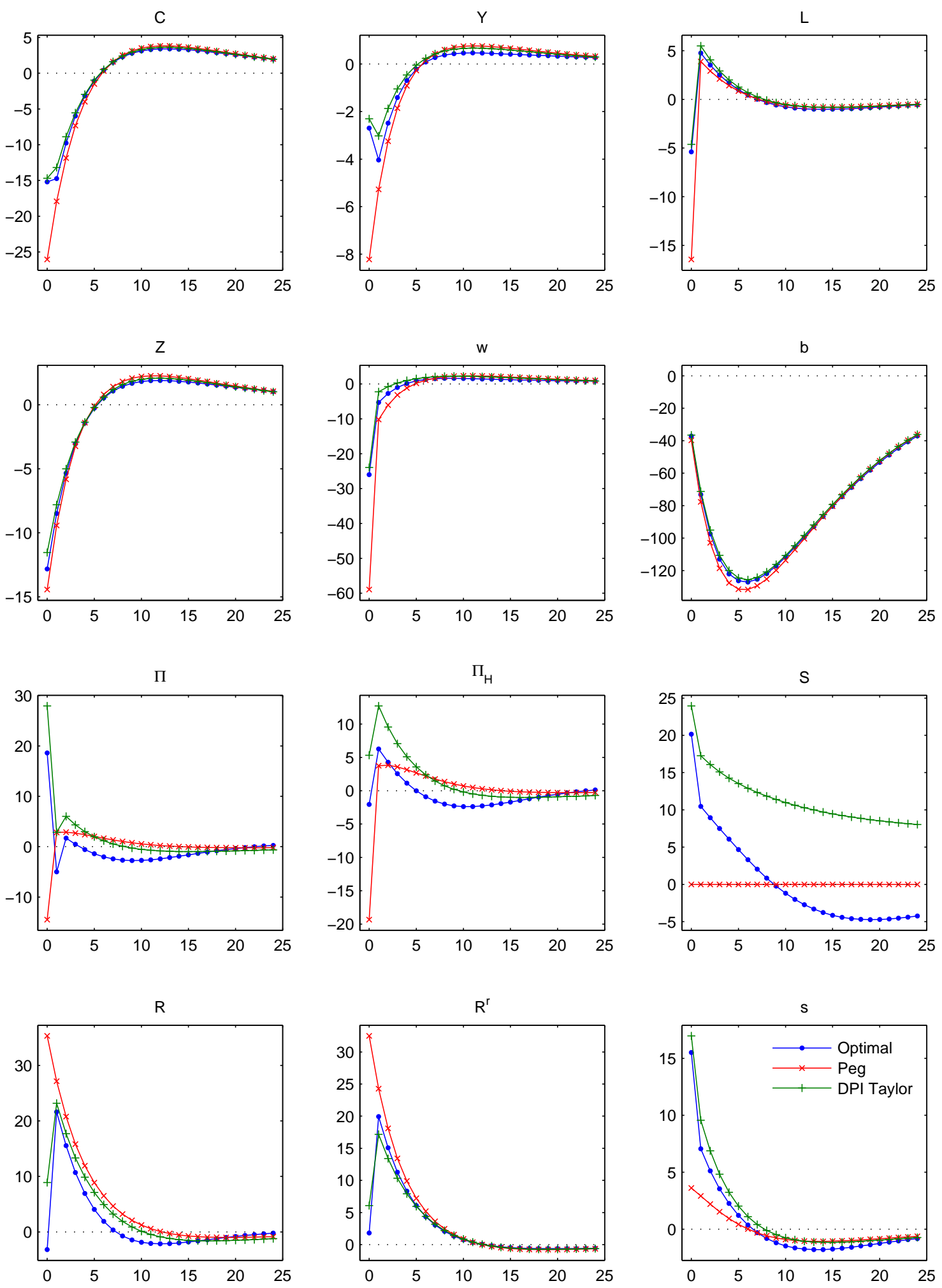


\section{Optimal Monetary Policy under Sudden Stops}

Figure 7: Responses under optimal policy and the best simple rule
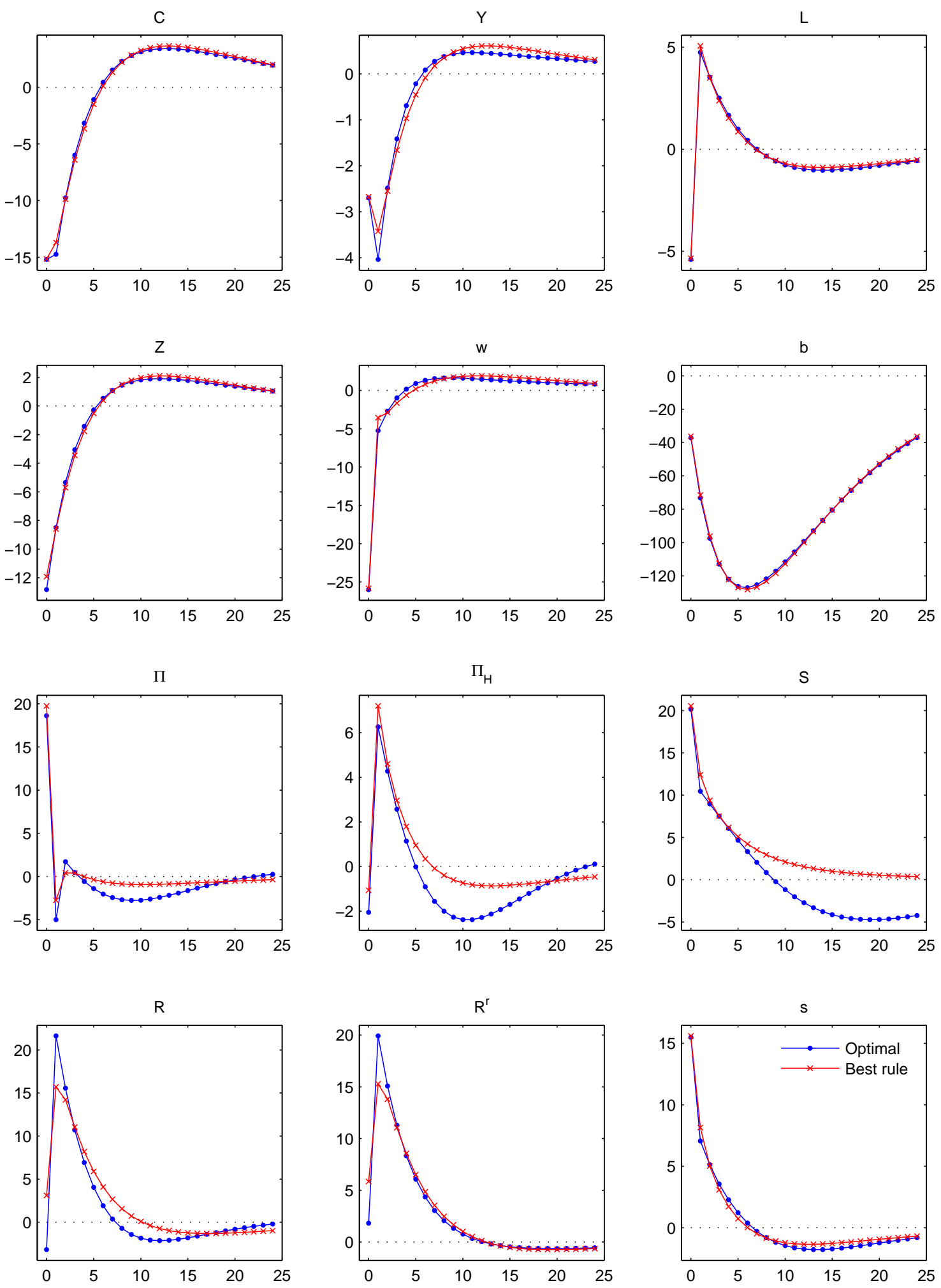